\title{
La Biblia en verso de Ignacio de Luzán (257 octavas inéditas)
}

\author{
GUillermo CARNERO \\ Universidad de Alicante
}

La Biblioteca Nacional de Madrid conserva, con la signatura Mss. 2528, un manuscrito en cuyo primer folio puede leerse lo que sigue:

HISTORIAE CELEBRIORES / VETERIS / TESTAMENTI / ICONIBVS REPRAESENTATAE / ET / Ad exitandas [sic] bonas Meditationes / selectis Epigrammatibus bonas meditationes [sic] / in lucem data [sic] / a / Christophoro Weigelio / NORIBERGAE. / 1712. / y con la tradución [sic] en verso castellano / de Dn. Ignacio Luzán / y de su mano y pluma. / V.B. / (Letra de D. Antonio Mori).

En 2 r. se añade, entre el original latino del primer epigrama y su traducción, la siguiente nota:

Tradución [sic] castellana de Dn. Ignacio Luzán, y de su propia letra según el original que conserva Dn. Manuel de Yera en Cádiz ${ }^{1}$.

En 28 r. se copia este nuevo título:

1. Mis pesquisas en documentación y bibliografía gaditanas (en lo que me ha prestado decisiva ayuda el prof. Alberto González Troyano) no han dado resultado que permita localizar a los sres. Yera y Mori. Por ellos hubiera acaso podido colegirse la procedencia del manuscrito. 
HISTORIAE CELEBRIORES / NOVI / TESTAMENTI / ICONIBVS REPRAESENTATAE / ET / Ad excitandas bonas meditationes / selectis Epigrammatibus exornatae / in lucem datae / a / Christophoro WEIGELIO / NORIBERGAE / y la tradución [sic] en verso castellano de / Dn. Ignacio Luzán / y de su mano y pluma.

El manuscrito es sin duda copia de otro, por sus errores y omisiones; una copia apresurada, pobre y no muy cuidada. Las cuestiones que de inmediato plantea son dos: qué original es la fuente de la traducción,, y si esta labor puede ser atribuida al conocido autor de la Poética.

Ese original es una selección de temas bíblicos en dos volúmenes, uno para cada Testamento; en la edición que manejo, y que creo la más antigua, publicados sin año en Nuremberg, y fechada la dedicatoria en 1708. Se trata de una hermosa edición, en la que cada página incluye un grabado alusivo al episodio que, debajo, se resume y glosa en cuatro versos latinos seguidos de su versión alemana. Pude localizar esta Biblia, tras una laboriosa búsqueda, en la Fürstlich Fürstenbergische Hofbibliothek, una pequeña biblioteca de Donaueschingen (Baden-Württemberg) ${ }^{2}$. El autor y editor es el célebre grabador Christoph Weigel (†1726), especializado en la impresión de obras de arte, antigüedades y heráldica.

En cuanto al Ignacio Luzán a quien se atribuye la traducción, la prudencia aconsejaba tomar en cuenta la posible autoría del Padre Ignacio Luzán, contemporáneo de su más famoso homónimo.

Jaime Finestres nos dice, en su Historia de Poblet ${ }^{3}$, que el P. Luzán fue abad de Piedra de 1732 a 1736; nada sobre su obra literaria. Latassa ${ }^{4}$ añade que nació en Albalate del Arzobispo, que era devoto de S. Inocencio, orador de mérito y autor de sermones como el dedicado a la Virgen de Arcos (Zaragoza, Francisco Moreno, 1735). Vi-

2. Quiero dar las gracias a los profesores Hans Juretschke (Instituto Germano-español Görres del C.S.I.C., Madrid), Hans Flasche (Univ. de Bonn) y Horst Hilger (Zentralkatalog Baden-Württemberg), por su inapreciable ayuda en la localización de ediciones de Weigel en bibliotecas alemanas; a la srta. Gisela Holzhüter, de la antes citada, que autorizó la reproducción, y al sr. Georg Goerlipp, que en Enero de 1986 fotografió con paciencia benedictina las Historiae para mi uso.

3. Historia de el Real Monasterio de Poblet..., vol. II, Cervera, Joseph Barber, 1753; «Catálogo de los Abades de el Real Monasterio de Santa María de Piedra..." (pp. 150 y ss.), p. 176.

4. M. Gómez Uriel, Bibliotecas Antigua y Nueva de Escritores Aragoneses de Latassa..., vol. II, Zaragoza, Impta. C. Ariño, 1885, p. 194. 
cente de la Fuente, en su continuación de la España Sagrada ${ }^{5}$, copia de Finestres sin más adición que el segundo apellido del abad, Ayuda. Jiménez Catalán ${ }^{6}$ recoge la Oración histórica, panegyrica y gratvlatoria [...] a la Soberana Imagen de María Santísima de los Arcos... (Zaragoza, Francisco Moreno, 1736), que a su vez atribuye Palau al otro Luzán.

Ni una palabra sobre el abad en la bibliografía cisterciense que, a partir de Muñiz (1793), he podido consultar?

No hay pues indicio alguno que permita atribuir la traducción de Weigel al abad Ignacio Luzán y Ayuda.

En cuanto a Ignacio de Luzán Claramunt, no conozco referencia a nuestro ms. 2528 ni a su contenido en la bibliografía. Nada dice Juan Ignacio de Luzán en el «Indice de las obras» ni en la "Vida» que contiene el ms. 17521 de la misma Biblioteca Nacional de Madrid; pero la ausencia no me parece concluyente, pues tampoco se cita ahí, por ejemplo, el Informe sobre Casas de Moneda ${ }^{8}$. Sí refiere en cambio Juan Ignacio que su padre estudió latín en sus años juveniles y que, estando en Palermo, pensó en hacerse sacerdote (ms. cit. 41 v.); y habla de amigos residentes en Alemania y Viena ( 42 v., 44 r., 59 v.). De ellos pudo obtener Luzán el apreciable regalo que a todas luces era la Biblia de Weigel, si no de una requisa de su tío el inquisidor. Es verosímil que Luzán emprendiera la traducción como ejercicio de latinidad.

5. España Sagrada, continuada por la Real Academia de la Historia..., vol. L, Madrid, Impta. J. Rodríguez, 1886, pp. 273-274.

6. Ensayo de una tipografía zaragozana del siglo XVIII, Zaragoza, Tip. La Academia, 1929 , pp. 183-184.

7. Roberto Muñiz, Biblioteca cisterciense española, Burgos, Josep de Navas, 1793; Eugène Manning, Dictionnaire des auteurs cisterciens, Rochefort, Abbaye Nôtre-Dame de Sr.Rémy, 1975; Guido Gibert, "Los estudios en la congregación cisterciense de los reinos de la corona de Aragón y Navarra», en VV.AA., Los monjes y los estudios, Abadía de Poblet, Tarragona, 1963, pp. 381-401; C. de la Fuente Cobos, «El Monasterio de Sta. M." de Piedra", N. de Diego, "Fuentes documentales sobre el Císter aragonés", D. Yáñez, "Presencia del Císter en Aragón a través de sus monjes ilustres", en VV.AA., El Císter. Ordenes Religiosas Zaragozanas, Zaragoza, Inst. Fernando el Católico, 1987, pp. 141-164, 101-118, 233-325.

Agradezco en este punto la asesoría de Fr. Damián Yáñez (mon. ${ }^{\circ}$ Osera, Orense), PP. Alejandro Masoliver y Agustín Altisent (mon. ${ }^{\circ}$ Poblet, Tarragona) y D..$^{a}$ Natividad de Diego (directora de la sección de Clero del A.H.N.). La profesora Aurora Egido localizó a petición mía la Oración en la Biblioteca Universitaria de Zaragoza.

8. A.H.N., Estado, legajo 2941. Véase mi artículo «El Informe sobre Casas de Moneda de Ignacio de Luzán; un proyecto de reforma monetaria en la España de Fernando VI", en prensa en el Homenaje a Antonio Vilanova, Barcelona, Universidad. 
Por otra parte, nuestro ms. 2528 incluye en 47 r. y v. un «Indice de las obras de Luzán» que no permite dudar de que el allí antes citado se entiende ser el autor de la Poética.

El corto ingenio, la ramplonería y el conceptismo del original no ofrecían mucho horizonte al traductor, que unas veces es brillante, otras correcto y otras torpe e incorrecto lingüística y métricamente, con el pie forzado de la estrofa elegida, la octava octosilábica con rima de romance. En cualquier caso, tenemos doscientas cincuenta y siete octavas hasta ahora desconocidas.

En la transcripción del ms. numero las estrofas y pongo su título en mayúscula; suprimo los originales latinos copiados de Weigel e incluyo algunas de las láminas. No sigo el mayusculismo arbitrario del original y distingo porque, por que, por qué, sino, si no, etc. Añado en nota las aclaraciones a referencias bíblicas que me parecen exigirlo. 


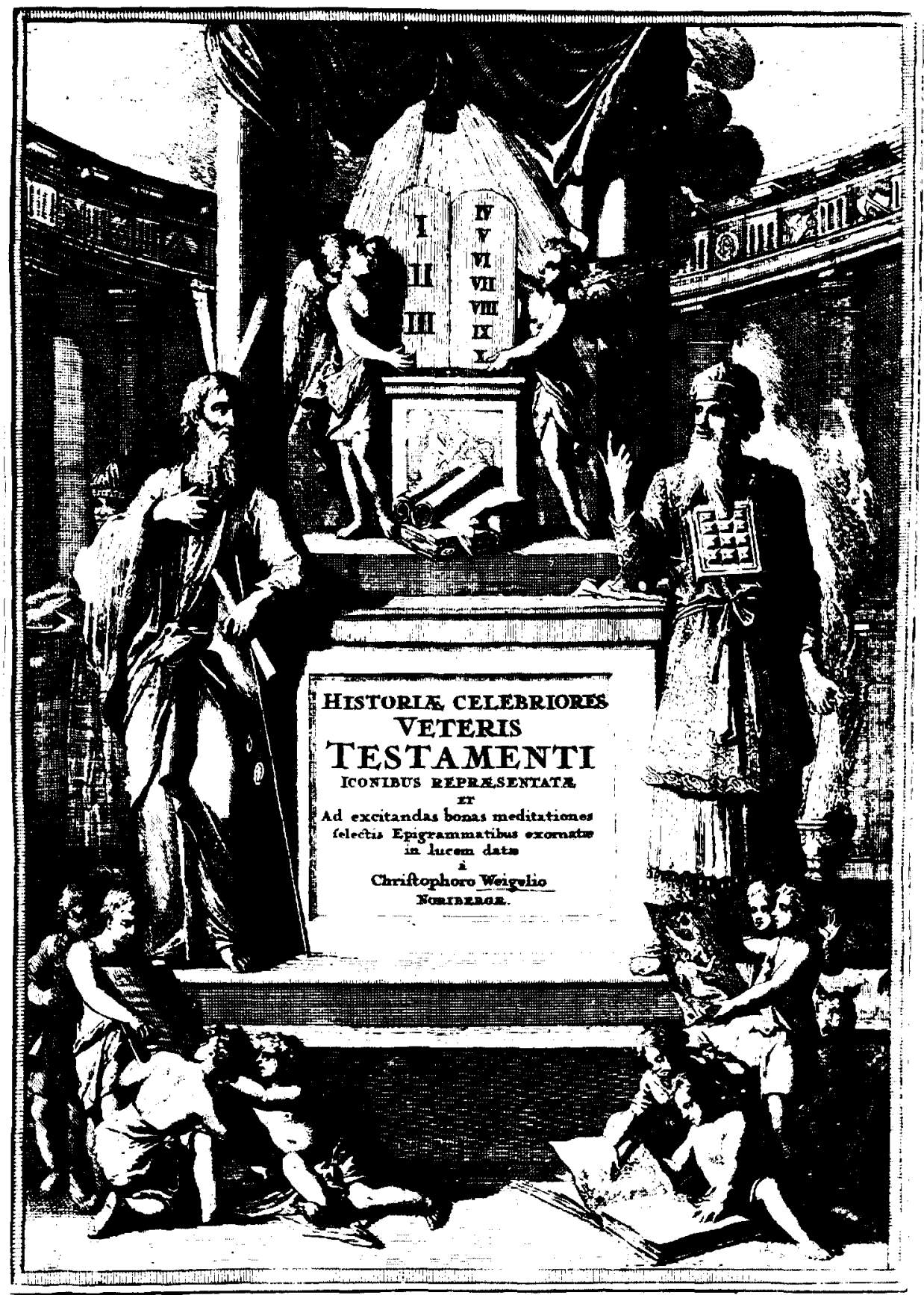


$1 \mathrm{r}$.

\author{
HISTORIAE CELEBRIORES \\ VETERIS \\ TESTAMENTI \\ ICONIBVS REPRAESENTATAE \\ ET
}

Ad exitandas [sic] bonas Meditationes

selectis Epigrammatibus bonas meditationes [sic]

in lucem data [sic]

a

Chistophoro Weigelio

NORIBERGAE

1712.

y con la tradución [sic] en verso castellano

de Dn. Ignacio Luzán

y de su mano y pluma.

V.B.

(Letra de D. Antonio Mori)

$1 \mathrm{v}_{.}=$en blanco

$2 \mathrm{r}$.

I - PECADO DE ADAM

Tradución [sic] castellana de Dn. Ignacio Luzán, y de su propia letra según el original que conserva Dn.

Manuel de Yera en Cádiz

En medio del Paraíso

la astuta serpiente engaña

a Eva, y ella cariñosa

su esposo con la manzana.

Con el ierro de tus padres

primeros aprender trata,

ó posteridad, que no hai

lugar libre de asechanzas. 
II - CASTIGO DE ADAM

Assí del Paraíso arroxa un ángel vibrando fuego a los que quisieron ser iguales a Dios immenso. Ya la vergüenza i pobreza a su desnudez ha abierto los ojos, y ven entrambos lo que son y lo que fueron.

$2 \mathrm{v}$.

\section{III - MUERTE DE ABEL}

Aquí iace Abel, a quien la bárbara diextra mata de su hermano, aborrecido sólo porque al Cielo agrada. El pérfido Caín huie por más que el mundo se halla vacío, porque el delito le atormenta y le amenaza.

\section{IV - EL DILUVIO UNIVERSAL}

Mira el mundo que perece en avenidas de aguas, reservando del peligro sola a su artífice el arca. Apartad, hombres, la mente de las amorosas llamas, pues sobre tales incendios llueve vengadora el agua.

\section{V - SALIDA DEL ARCA}

Baxa el agua i se descubre la tierra, parece el arca, Noé sale, vuela el ave i de allí la fiera salta. Porque Dios quiere que todo cresca otra vez, se restaura el mundo y logra este nombre limpio ya con tantas aguas.
$3 \mathrm{r}$.

VI - SALIDA DEL ARCA Y SACRIFICIO DE NOÉ

Agradecido Noé

da a Dios gratos holocaustos, hácese la paz y el iris es la señal del contrato. Sobre este iris algún día se sentará el juez airado; tema de Dios enemigo el hombre que quiebra el pacto.

\section{VII - TORRE DE BABEL}

Quando a los aires se eleva la torre, Dios enojado de los hombres el lenguaje confunde en sonidos varios ${ }^{9}$. Nuestro nombre, decían ellos, pongamos sobre los astros; pecó su soberbia lengua pero pagó sú pecado.

\section{VIII - VOCACION DE HABRAHAM}

A otra región desterrado assí, por mandarlo Dios, desde los paternos campos camina Abraham con Loth. Con sus costumbres el justo illustra, con luz el Sol el mundo: luego no nacen a un solo pueblo los dos.

$3 \mathrm{v}$.

IX-MELCHISENÉ Y ABRAHAM ${ }^{10}$

Después que a los enemigos arroxa i a Loth redime Abraham, los panes i el vino de Melchisedech recibe. Pero del rey de Sodoma los dones desprecia viles, que el justo no su interés sino el del pueblo mide.

9. El ms. dice "graves", por error.

10. Génesis XIV. Tras la batalla entre los reyes de Sodoma, Gomorra, Adama, Seboyim y Bela contra los de Elam, Goyim, Senaar y Elasar, derrotados los primeros, en el sa- 


\section{$X$ - EL REY DE GERARA $Y$ ABRAHAM ${ }^{11}$}

El rey de Gerara, huiendo

del Cielo iras ${ }^{12} \mathrm{i}$ amenazas

le da dones a Abraham

y le restituie a Sara.

Creemos que a los delitos

eternas penas aguardan,

pero, iquién teme del otro

ver la justicia violada!

\section{XI - LOTH}

Loth y sus hijas caminan sin volver atrás la cara a las perversas ciudades que Dios con su fuego acaba.

Pero su muger, que mira, de sal se vuelve en estatua. ¡Ó, si su fragilidad con esta sal se enmendara!

$4 r$.

XII - HOSPITALIDAD DE ABRAHAM ${ }^{13}$

A tres ángeles la mesa el piadoso Abraham prepara; la sucesión le prometen, búrlase la anciana Sara. Mereció castigo, que es delito la desconfianza quando el que habla no puede engañarse en lo que habla.

\section{XIII - AGAR DESTERRADA}

Con tu hijo a los desiertos sales, Agar, desterrada; tu dueño Abraham no lo estorba, zelosa Sara lo manda. No por esto te abandona Dios quando lloras tus faltas; ia por las lágrimas tuias te dará copiosas aguas.

\section{XIV - ISMAEL SOCORRIDO}

Congoxada ruega al Cielo por su hijo a quien la sed mata la madre, y después se alegra con las aguas señaladas. El chico Ismael recobra fuerzas con beber el agua. Aprende: Dios, quando ruegan, los infelices ampara ${ }^{14}$.

$4 \mathrm{v}$.

XV - SACRIFICIO DE ABRAHAM

Mirad de Abraham el cuchillo, padres de blandas entrañas, con el qual su amado hijo sacrificar no retrasa.

Vosotros no perdonéis vuestro hijo, si Dios lo manda; pocas víctimas entonces irán a la Estigia llama.

queo de Sodoma y Gomorra fue capturado Lot, sobrino de Abraham; éste salió en persecución de los captores y los venció. Al regresar, Melquisedec, rey-sacerdote de Salem, bendijo a Abraham. El rey de Sodoma ofreció a Abraham las riquezas capturadas a los saqueadores, pero él las rechazó admitiendo sólo la parte debida a los caudillos que lo habían acompañado.

11. La estrofa ocupa el lugar 12 en Weigel. Génesis XX. Abimelec, rey de Guerar, secuestró a Sara creyéndola hermana de Abraham, cosa que ambos habian fingido. Dios se le apareció en sueños y le ordenó restituirla, cosa que hizo el rey añadiendo un regalo.

12. «iras» duplicado en el ms.

13. Estrofa que ocupa el lugar 10 en Weigel.

14. «amparan» en el ms. 


\section{XVI - REBECA}

A los criados de Isac i a los cansados camellos

Rebeca del fresco pozo ofrece cántaros llenos. Esta dignación, ó virgen, te dio esposo no pequeño, que es rara prenda virtud y hermosura en un sugeto.

\section{XVII - ESAÚ VENDE SU MAYORASGO}

Esaú, vendedor necio, a Jacob jura la venta i todo su mayorasgo da por las rubias lentejas. Del padre, la tierra y cielo a un tiempo la gracia dexa. ¡O, quántas riquezas pierde de la gula la baxeza!

\section{$5 \mathrm{r}$.}

\section{XVIII - BENDICIÓN A JACOB}

Jacob, a quien de cabrito con pieles viste su madre, el vendido mayorasgo logra de su ciego padre. Assí una muger entonces con ardid i a un ciego sabe engañar; pero aora tiene a un Argos que rezelarse ${ }^{15}$.

\section{XIX - ESCALA DE JACOB}

Ésta es la escala que junta la tierra al Olimpo excelso; por aquí suben y baxan los moradores supremos.
La escala es la vía de cruz que Jesús passó primero; el que el de la cruz rehúsa huie el camino del Cielo.

\section{XX - JACOB SIRVE POR RACHEL ${ }^{16}$}

Mira aqui a Jacob, que alegre servir siete años sufrió, i mira a Rachel, por quien estos siete años sirvió. Si la cara de una hermosa doncella a esto le obligó, di, ¿lograrás sin trabaxo gozar a la cara de Dios?

$5 v$.

\section{XXI - LUCHA DE JACOB CON EL ANGEL ${ }^{17}$}

¿Qué lucha es ésta? Del Cielo oprime a un ángel Jacob i le tiene hasta que ofresca los bienes que deseó. Jusgo que con esta lucha la Deidad nos enseñó que nadie después espere dones si no trabaxó.

\section{XXII - ESAÚ SE RECONCILIA CON $\mathrm{JACOB}$}

Esaú, a quien postrado adoras, ya te recibe, ó Jacob, i aunque está armado con mil cariños te admite. Aprended, mortales, quánto un rendimiento consigue, pues que pudo conciliar destos hermanos las lides.

15. Génésis XXVII-XXVIII. Alusión al odio de Esaú contra Jacob.

16. Génesis XXIX. Enamorado Jacob de Raquel, sirve a su padre Labán durante siete años para obtenerla, pero en la noche de bodas éste conduce al lecho a su otra hija, Lía; descubierto por la mañana el cambio, Jacob reclama y obtiene a Raquel a cambio de otros siete años de servicios futuros.

17. Génesis XXXII. Jacob lucha toda la noche con un desconocido y se niega a dejarlo marchar hasta haber logrado su bendición. El desconocido, en realidad un ángel, cambia el nombre de Jacob por el de Israel. 
XXIII-DINA ${ }^{18}$

La fuerza que se hizo a Dina castigan la fuerza i armas;

Sichem i los ciudadanos mueren al filo de espadas.

:Ay de nosotros! Si assí

Dios sus offensas vengara,

a penas en todo el mundo

algún morador quedara.

$6 \mathrm{r}$.

\section{XXIV - JOSEPH VENDIDO}

Venden a Joseph, que a Egipto ha de passar hecho esclavo. ¿Quién le vende? Llena de ira, la turba de sus hermanos. ¿Ó maldad, el innocente en vil moneda apreciado! Pero aún no ve nuestro siglo aqueste error desterrado.

\section{XXV - PRESENTAN LA TÚNICA DE JOSEPH A JACOB}

Jacob, engaño padeces con la toga ensangrentada, quando juzgas que tu hijo de una fiera dio en las garras. Pero la péssima fiera daña a tu hijo, no te engañas, que ninguna es peor fiera si a la envidia se compara.

\section{XXVI - CASTIDAD DE JOSEPH}

De la más impura mano, Joseph castíssimo, escapa; más cruel que una serpiente es la muger que te abraza.
Pero, ¿para qué al que huie necia le quitas la capa?

En vano es: ningunos velos pueden ocultar ta infamia.

$6 v$.

XXVII - JOSEPH EN LA CÁRCEL

\section{Restituidos honores}

Joseph anuncia al copero pero fatales desgracias a tu vida, ó panadero ${ }^{19}$. Aquél su profeta olvida en el palacio soberbio donde igualmente carecen de agradecidos i buenos.

\section{XXVIII - JOSEF EXPLICA LOS SUEÑOS DE FARAÓN}

Joven profeta los sueños a Pharaón le descubre que no puede descifrarle de viejos la muchedumbre. Ó Joseph, tu castidad en los futuros te instruie, que de ojos puros la luz más i más de lexos luce.

\section{XXIX - JOSEPH RECONOCIDO POR SUS ERMANOS}

El sueño, ó casto Joseph, verdades te manifiesta: ves aquí adorar tus plantas humilladas las estrellas ${ }^{20}$, que tus culpados hermanos las Hyadas representan, que a deshacerse en su llanto los precisa la vergüenza.

18. El príncipe Siquem secuestra y viola a Dina, hija de Jacob y de Lía. Los hermanos de ella matan a todos los súbditos de Siquem. Génesis XXXIV.

19. Génesis XL. El copero y el repostero mayor del faraón son encarcelados junto a José; ambos tienen un sueño, que éste interpreta: el copero será restituido en su cargo, y el repostero decapitado, a los tres días.

20. Génesis XXXVII. Alusión al sueño en que José vio que el Sol, la Luna y las estrellas lo adoraban, lo que motiva, unido al sueño anterior de los haces de espigas, que sus hermanos proyecten matarlo y lo vendan finalmente a los ismaelitas que lo llevan a Egipto. 


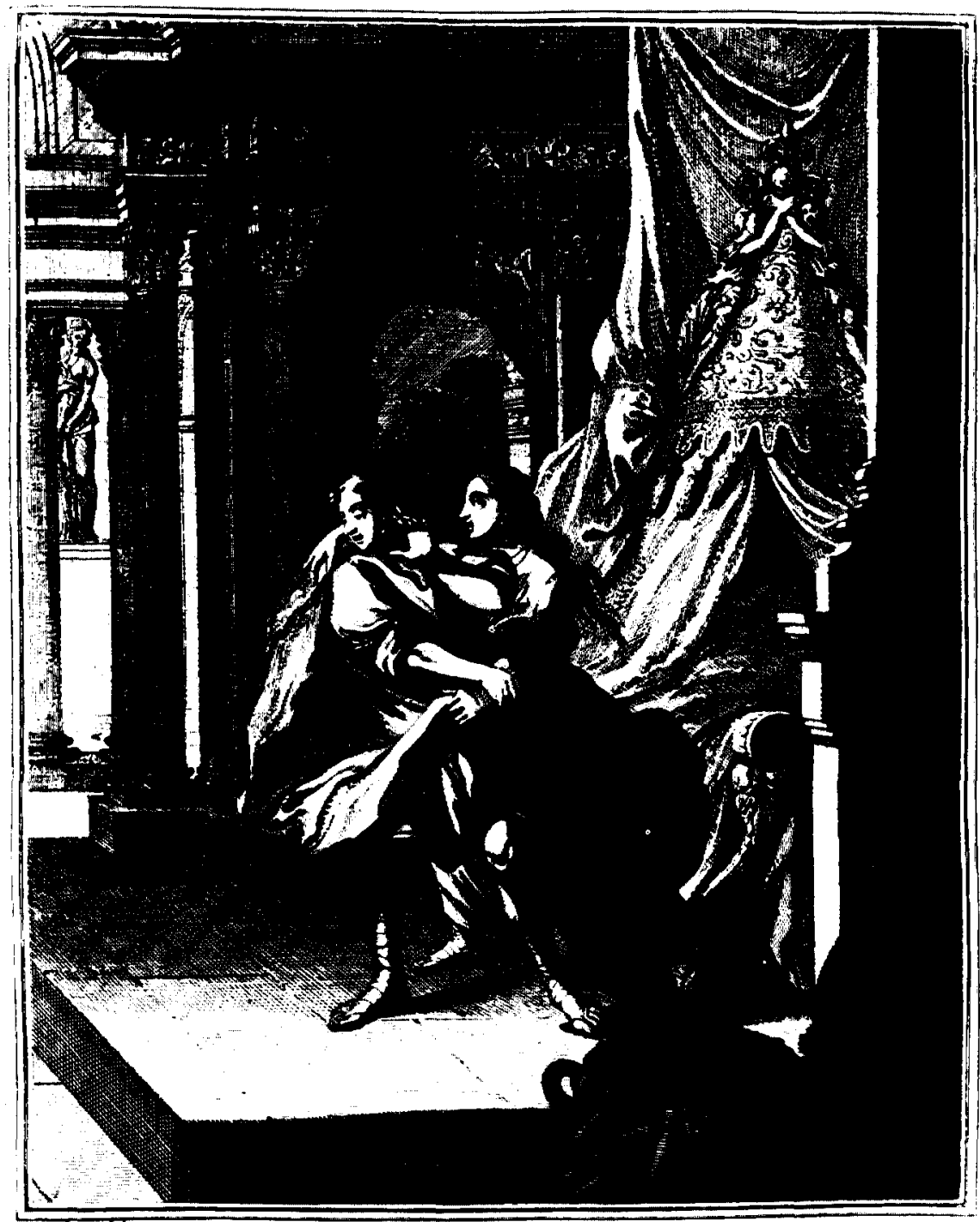

limpe to unpurat Gosephe cistissunc dextrat

Aniplexir est Mulier savion angue suo

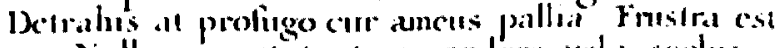

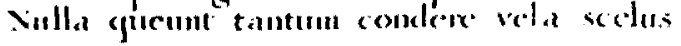

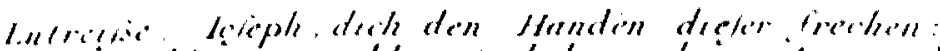

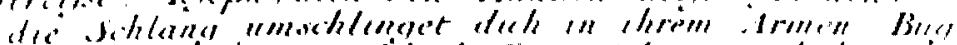

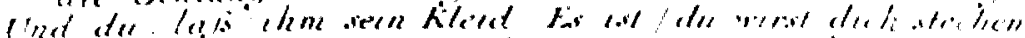

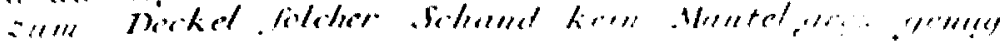

Castidad de Joseph 


\section{XXX - LOS ERMANOS DE JOSEPH DAN CUENTA A JACOB}

Los hermanos de su hermano las honras i vida qüentan, pero el padre con que viva Joseph sólo se contenta, i con razón de su vida, no de sus dichas, se alegra; que siendo virtuoso i vivo su hijo, nada más desea.

\section{XXXI - JOSEPH SE PRESENTA A SU PADRE JACOB}

Mira a Jacob y a Joseph cómo a abrazarse se acercan, i aprende de aquí que vienen los gustos tras de las penas. Aquella toga que al padre en la sangre de la fiera le afligió antes salpicada, púrpura aora le alegra.

\section{XXXII - BENDICIÓN DE JACOB A SUS HIJOS}

Jacob, ya para morir, a sus hijos pronostica sus sucessos, i fallece deseando a todos mil dichas. $A$ las últimas palabras de tu padre, ó hijo, mira, que tal vez hace la muerte que paresca que adivinan.

$7 \mathrm{v}$.

\section{XXXIII - MOYSÉS SACADO DEL RÍO}

La hija del rey ve en las aguas a Moysés, a quien su padre quería matar; le libra i le cría como infante. Assí la alta Providencia la astucia humana deshace; con la misma arte que estudia perderle, sabe librarle.

\section{XXXIV - MOYSÉS CASTIGA A UN EGIPCIO}

La muerte a aquel que, culpado, la dio al hebreo innocente, siendo el vengador, Moisés da el castigo que merece. Pharaón, ya hai a quien temas; porque la mano que tiene tanta fuerza ha de admirarte quando tu vara govierne.

\author{
XXXV - LA SARZA QUE VIO MOYSÉS \\ Ó Moysés, con pies desnudos \\ adora la Deidad sacra \\ que está escondida en el fuego \\ en que se quema la zarza. \\ No temas, embaxador \\ embiado a la aula gitana 21 , \\ porque essa llama que miras \\ dará fuerza a tus palabras.
}

$8 \mathrm{r}$.

\section{XXXVI - TRABAJOS DE LOS HEBREOS EN EGIPTO}

Del insufrible trabaxo

el pueblo hebreo se quexa. ¡Pero qué hace Pharaón! Más trabajos les aumenta, que es costumbre de tiranos querer aumentar sus fuerzas oprimiendo más i más de sus pueblos las cabezas.

\section{XXXVII - VARA DE MOYSÉS}

La admirable vara al suelo arroxada, sierpe se hace y se traga las culebras obras de inágica arte. Teme, o Pharaón: la vara que tantas sierpes deshace, aun que en dragón te conviertas, la ponzona ha de quitarte.

21. Gitano, egitano o egiptano = egipcio. 
XXXVIII - PLAGAS DE EGIPTO: LAS AGUAS EN SANGRE

Mira las fuentes y el mar vueltos de color de sangre que muestran, cruel tyrano, tu delito i penas graves. Por ti del pueblo el sudor con sangre llegó a mesclarse, y éste hará que del Mar Roxo las altas olas te traguen.

$8 v$.

\section{XXXIX - PESTE DEL GANADO}

Todo el ganado consume la cruel peste; en todas partes los cadáveres los campos cubren, i podridos iacen. En nada ofendió el ganado, pero la bestia indomable del tyrano aprender pudo destas penas sus ultrages.

\section{XL - DE LOS HOMBRES}

Otra vez con llagas vuelven los cuerpos de Egipto a hincharse; de aquí los hombres fallecen, de allí los ganados iacen. Pero, ¿por qué al rey cruel esta pena no combate? Porque ia su hinchazón avía hecho que enfermasse.

\section{XLI - GRANIZO}

Todo lo que hai en las selvas, todo lo que halla en los campos hiere cruel granizo embuelto en truenos y rayos. ¿Ó Pharaón duro, en quien, aunque rompan los peñascos, no mueven el corazón los rayos aun duplicados!

\section{XLII - MUERTE DE LOS PRIMOGÉNITOS}

Por todas partes la muerte destruye los mayorasgos;

Dios lo quiere, aun el rey mismo llora de su hijo el estrago. Ahora dexa a los hebreos, que no mueve a los tyranos solo el daño de su pueblo si no es con su propio daño.

\section{XLIII - PRIMERA PASQUA \\ Con báculos i ceñida la cintura, de la Pasqua come de prissa el cordero ${ }^{22}$ de Abraham la fíel prosapia. Si el cordero comer quieres que al mundo las culpas lava. has de tener casto amor, fee viva, firme esperanza.}

\author{
XLIV - EL MANÁ \\ Cógese el rosío que \\ quaxado del cielo cae, \\ cuia celestial comida \\ del pueblo sacia la hambre. \\ Si a los hambrientos comida \\ desde el cielo se le trahe, \\ ¿quién negará que allí está \\ de los hombres el Gran Padre?
}

$9 \mathrm{v}$.

\section{XLV - DA AGUA A LA PIEDRA}

Assí en otro tiempo pudo sacar de las piedras agua del insigne bicornuto varón la admirable vara ${ }^{23}$. Más que esta vara tu cruz puede, ó Jesús; luego el alma que las lágrimas resiste más dura que el mármol se halla.

\footnotetext{
22. Éxodo XII: «El día diez de este mes, tome cada uno según las casas paternas una res menor por cada casa [...] Habéis de comerlo así: ceñidos los lomos, calzados los pies y el báculo en la mano, y comiendo deprisa; es la Pascua de Yahvé».
}

23. Éxodo XXXIV - Transfiguración de Moisés. 


\section{XLVI - CASTIGO DE LOS AMALECITAS ${ }^{2+}$}

Por aquí de Josué

los Amalecitas carga

la mano; de allí Moysés

al cielo las suias alza.

Quando la piedad les da

la fuerza, triumphan las armas

porque siempre es invencible

mano a quien Dios acompaña.

\section{XLVII - MOYSÉS ELIGE JUECES}

Jetro $^{25}$ a Moysés aconseja

que ministros fieles junte

a quienes de sus cuidados

alguna parte acumule.

El que para muchos vela

i a muchos a un tiempo acude

muchos ojos, muchas manos

es preciso que vincule.

$10 \mathrm{r}$

\section{XLVIII - MOYSÉS EN EL MONTE SINAÍ}

Entre fulminantes llamas,

vibrando truenos el cielo, habla el gran Dios de Israel i da la Ley a su pueblo.

Quando tiene el corazón

duro, oído mal dispuesto

el vasallo, el rey entonces

manda bien con voz de trueno.

\section{XLIX - EL ARCA}

Tu imagen fue Arón, ó Christo,

i en el corazón impressos

en doce piedras preciosas

traxo los nombres del pueblo ${ }^{26}$.

Tu amor en la cruz descubre

traes los fieles en el pecho:

en el libro de la vida

quien permanece está puesto.
L - BECERRO DE ORO

Quiebra las tablas, Moysés, de la Ley que Dios te dio, porque ya iace a los pies del pueblo que la quebró. Puesto que ya salta i juega, come i bebe, bien mostró que parecerse en costumbres quiere el ternero su dios.

$10 \mathrm{v}$

\section{LI - RACIMO DEL PAÍS DE PROMISIÓN}

Qué feliz la tierra fue que produjo aquel racimo, a quien apenas dos hombres en el hombro han sostenido. Pero aora, quando qüentan que un hombre gasta sus vinos, qué estéril se ha buelto el suelo, dándole el cielo el castigo.

\section{LII - LA SERPIENTE DE METAL}

El metal, la sierpe, Christo

al pecador representa; aquél no tiene veneno, éste de culpa se exempta. Aquél a los cuerpos, éste salud al alma franquea: luego a Jesús en la cruz si estás enfermo te acerca.

\section{LIII - LA BURRA DE BALAAM 27}

¿Por qué me hieres, Balaam, si del camino me apartan?, fue lo que habló en otro tiempo con voz prodigiosa el asna.

Si quando vamos por sendas vedadas nos avisaran, juzgo que el hablar los asnos no fuera cosa tan rara.

24. Éxodo XVII.

25. Éxodo XVIII. Jetro es suegro de Moisés.

26. Exodo XXVIII. En realidad, dos ónices colocados en las hombreras del efod de Aarón.

27. Números XXII. 


\section{LIV - PASO DEL JORDAN}

Huie una corriente, i otra como alto monte se para; assí el Jordán descubrió seco camino en sus aguas. Por aquí al puebio encamina Josué, que nada embaraza al capitán que en favor del cielo mueve sus armas.

\section{LV - EL ÁNGEL SE APARECE A JOSUÉ}

Al punto Josué se postra luego que el ángel le avisa que es el mismo capitán de la celestial milicia. ¡Ó, qué bien! Porque así debe sugetarse a tal divisa el capitán que quisiere tener victoria cumplida.

\section{LVI - CASTIGO DE ACHÁN28}

Parece el hurto; el perdón Achán pide, mas no alcanza, que ha de morir de allí a poco del pueblo con las pedradas. Si también assí los hurtos nuestros tiempos castigaran, dime, ¿dónde se hallaría suelo sin piedras tiradas?

$11 \mathrm{v}$

\section{LVII - ENGAÑO DE LOS GABAONITAS 29}

Engañado el capitán hebreo por cautelosas mentiras, a Gabaón pacto de paces otorga.
Con la muerte el pueblo quiere vengar el dolo,y lo estorba Josué, que príncipe tal le fee pactada no viola.

\section{LVIII - JOSUÉ PARA EL SOL}

Manda Josué al Sol se pare, párase, el día se alarga porque no huiga el enemigo de la noche con la capa. El capitán que quisiere que por sus soldados salga Dios, que es el sol de justicia, emprenda justas campañas.

\section{LIX - CASTIGO DE ADONIBESEC 30}

Vencido Adonibesec, de manos y pies cortadas las coiunturas, en cárcel de Jerusalem acaba. Assí cruel vencedor sus enemigos trataba, pero ya el mismo castigo contra su author se prepara.

$12 \mathrm{r}$.

\section{LX - SF́SARA 31}

El cápitán fugitivo

de su campo cananeo mescla la leche y la sangre, junta la muerte y el sueño. De Jabán la suerte iace, que para postrar su exfuerzo una muger con un clavo fixó a Sísara en el suelo.

28. Josué VII. Habiendo sido anatematizadas las riquezas de Jericó, Acán se apodera de parte de ellas; acto seguido los israelitas son derrotados en el asalto de Hai. Acán, su familia y su hacienda son lapidados y quemados.

29. Josué IX. Los gabaonitas conciertan mediante engaño una alianza con Josué, que la otorga y mantiene el juramento hecho en el nombre de Yahvé a pesar de haberse descubierto el engaño.

30. Jueces I.

31. Jueces IV. Jabín, rey de Canán, tiene por jefe de su ejército a Sísara. Un ejército is- 
LXI - GEDEÓN Y EL ÁNGEL ${ }^{32}$

El manjar, Gedeón, que ofreces

toca el ángel con su vara;

al punto el fuego que brota

de la piedra lo arrebata.

Alégrate, auspicio tienes;

assí el ardor de batallas

con tu guía pechos fríos

como el mármol hará un asqua.

\section{LXII - EL VELLÓN DE GEDEÓN ${ }^{33}$}

El capitán Gedeón

temprano el vellón levanta

moxado en la tierra seca,

seco en la tierra moxada.

La divina protección

con prodigios saber trata;

que sólo con Dios propicio

se han de emprender las batallas.

$12 \mathrm{v}$.

\section{LXIII - VOTO DE JEPTÉ ${ }^{34}$}

Su hija a Jepté vencedor sale a encontrar la primera, luego víctima ha de ser, muerta del padre a la diestra.

Entre tanto llorará

que sin prole alguna muera;

assí aora, casada, presto

la muger llorar rezela.
LXIV - EL ÁNGEL A MANÉ 35

Dos vezes del alto cielo a Mané se embía un ángel, primero es gusto de Dios, despues el ruego le trahe. Mira que fiel es la turba de ministros celestiales, ó hombre, cuán officiosos en tus deseos te valen.

\section{LXV - SAMSÓN MATA UN LEÓN}

¡Ó, qué fuerza tan terrible tubo de Samsón la diestra, que fue sufficiente a hacer pedazos tan cruel fiera! Pero postrará una loba a quien un león no hizo mella; luego al dolo mugeril no le iguala alguna bestia.

$13 \mathrm{r}$.

\section{LXVI - SAMSÓN MATA MIL FILISTEOS}

Con la quixada Samsón

a mil enemigos mata, i pone a dos mil restantes en fuga precipitada.

En este mundo guerrero quántas muertes se encontraran si hubiera tantos Samsones como se hallan tales lanzas.

raelita lo derrota y Sísara huye a la tienda de Jeber, cuya mujer, Jael, le ofrece leche y lo asesina hincándole un clavo en la sien.

32. Jueces VI. Sometidos los israelitas a los madianitas, un ángel se aparece a Gedeón y le profetiza que será el libertador de su pueblo. Pide Gedeón una señal, y un fuego sobrenatural consume las ofrendas que ha preparado.

33. Jueces VI. Gedeón pide otra señal: que un vellón de lana depositado por la noche quede por la mañana cubierto de rocío al mismo tiempo que la tierra a su alrededor permanece seca. Así ocurre, lo mismo que el prodigio inverso cuando Gedeón lo pide también.

34. Jueces XI.

35. Jueces XIII. Mané está casado con una mujer estéril, a la que se aparece un ángel que le promete descendencia. Una segunda visita ocurre a ruego de Mané. El hijo anunciado será Sansón. 


\section{LXVII - SE LLEVA LAS PUERTAS DE LA CIUDAD}

¿Para qué, Samsón, de noche a las philisteas ciudades las puertas quitas? En vano trabajas para escaparte. Aunque esté abierta, ninguna huida hará que te escapes, que el amor por los cabellos sabrá atado sugetarte.

\section{LXVIII - ROMPE LOS LAZOS CON QUE LO ATARON}

Rompe al punto, ó philisteos, los lazos con que le atasteis, que Samsón no ha de ser preso con estos engaños y arte. A este héroe sólo Amor, que vencer lo demás sabe, por los engañosos brazos vence de Dalila afable.

$13 \mathrm{v}$.

\section{LXIX - SAMSÓN DESPLOMA EL TEMPLO}

Mira: a los juegos del pueblo el ciego Samsón llevado, desploma con mano fuerte el magnífico theatro.

Feliz el que con su muerte logra la de sus contrarios, a quien su mismo sepulchro vencedor le está aclamando.

\section{LXX - MUERTE VIOLENTA DE UNA MUGER POR LOS DE BENJAMIN $^{36}$}

Ésta muere de los hombres oprimida a la violencia, pero hecha pedazos mueve a su venganza las diestras. De Benjamin deste modo muere la estirpe perversa, que Dios con ríos de sangre impuros fuegos anega.

LXXI - RUTH Y BOOZ

Ruth, que tras los segadores cuidadosa coge espigas, éssa te agrada i la escoges, Booz, que esposa te sirva. Ruth el alma, y el divino esposo Booz significa; Dios ama al que aun el menor con sumo desvelo estima.

$14 \mathrm{r}$.

\section{LXXII - ANA PRESENTA AL SACERDOTE SU HIJO ${ }^{37}$}

Ana a ti, ó gran sacerdote, el hijo avido con ruegos te presenta, i le consagra al culto de Dios eterno. Aora le ofrece al altar la madre de cera hecho alguna vez, mas el chico no permanece en el templo.

36. Jueces XIX-XX. Un levita que viaja con su concubina se acoge a la ciudad de Gueba, de la tribu de Benjamín, al sorprenderlo la noche. Los hombres de la ciudad exigen al que lo ha hospedado la entrega del forastero, y se contentan con violar a la concubina, que queda muerta. El levita corta el cadáver en doce pedazos que envía a las doce tribus de Israel con mensajeros que relatan el crimen. Se forma una confederación para castigar a los de Gueba, a los que apoyan los benjaminitas, que quedan casi totalmente extinguidos tras la batalla.

37. I Samuel I. Elcana tiene dos mujeres; una de ellas, Ana, estéril, ofrece a Dios consagrarle el hijo que logre tener, y que será Samuel. En la estrofa, alusión a los exvotos. 


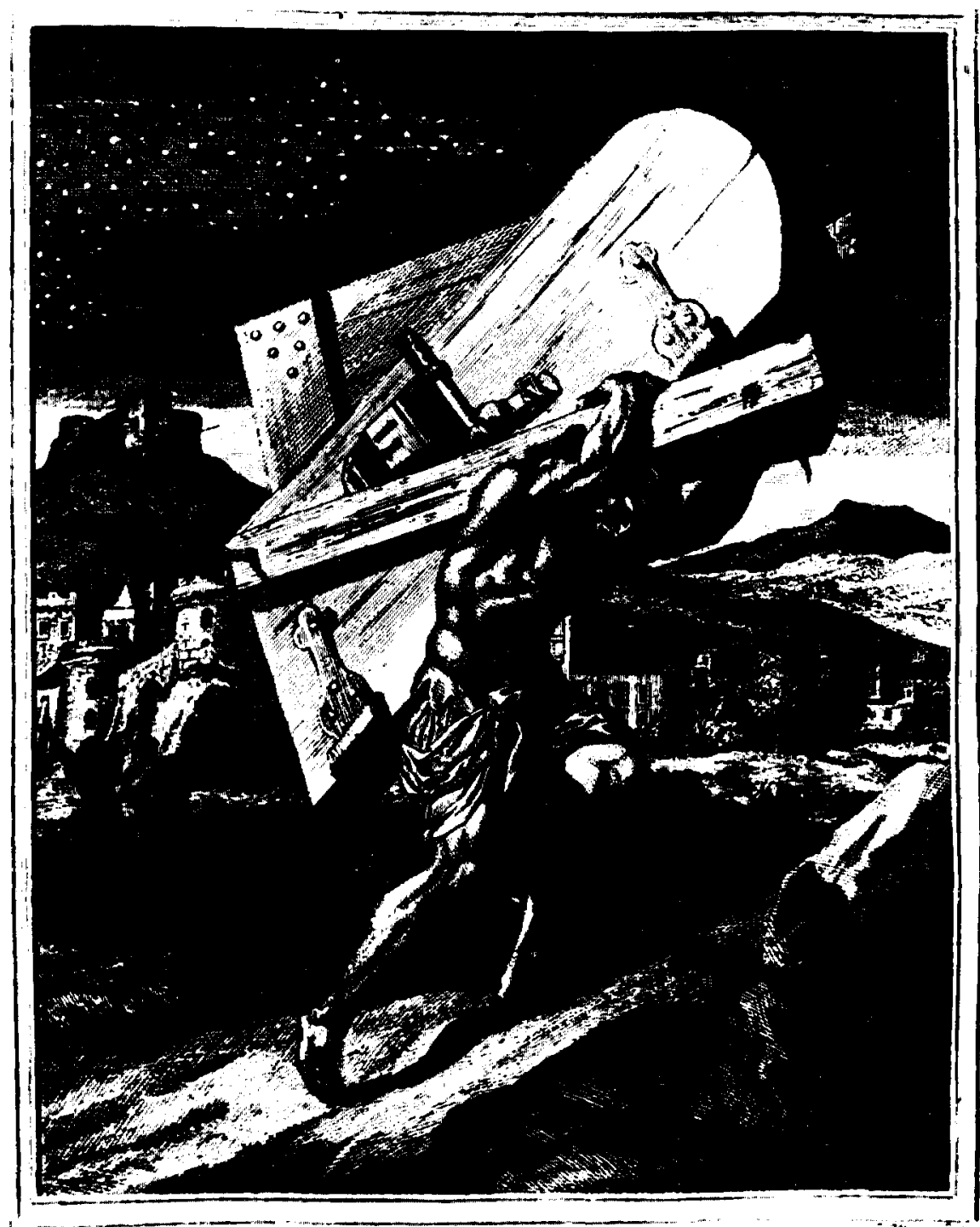

\footnotetext{
[1] T) XV.

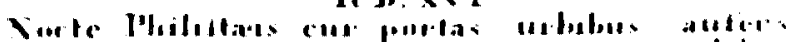

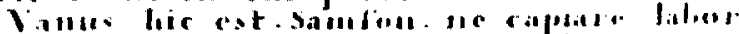

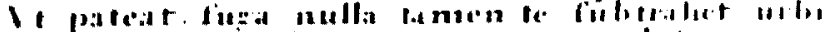

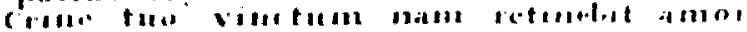

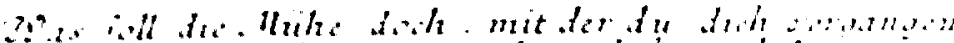

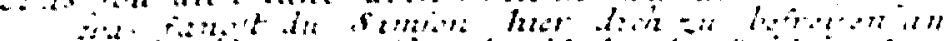

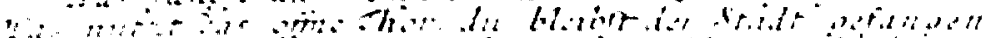

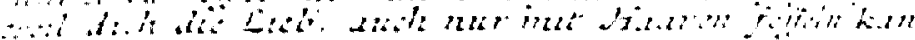

Se lleva las puertas de la ciudad 


\section{LXXIII - MUERTE DE HELI ${ }^{38}$}

Viendo destrozado el pueblo

i viendo el arca captiva, del delito de sus hijos

Helí comprimido expira. Caió i de lástima digno murió en la misma caída, porque los padres mui tiernos amedrente esta ruina.

\section{LXXIV - SAÚL UNGIDO ${ }^{39}$}

\section{Como rey unge a Saúl}

Samuel, porque Dios lo manda, quando de su padre busca a las fugitivas asnas ${ }^{40}$. ¡Ó, qué vien aquella gente de dura cerviz encarga a quien antes se entregó cuidar de especie tan tarda!

\section{LXXVI - SAMUEL AMENAZA AL PUEBLO}

Reprehende a los ingratos Samuel, i a lluvias i rayos los amenaza, i el miedo de la Deidad va insinuando. Promete a los buenos dones de Dios, su amor encargando. Aprende: al pueblo govierna temor con amor mesclado.

\section{LXXVII - SAÚL DETIENE A SAMUEL Y LE RASGA LA ROPA ${ }^{42}$}

Quando detiene al profeta

Saúl la ropa le rasga, i de que perderá el reino su mano el agüero guarda. Mira que aun los reyes mismos, si obliga la suerte amarga, detener quieren los buenos aun rasgándoles la capa.

$15 \mathrm{r}$.

\section{LXXV - LO ENCUENTRAN ESCONDIDO ${ }^{41}$}

Alto varón, ¿por qué buscas algún rincón de tu casa? ¿Por qué huies la corona que el mismo Dios te prepara? En vano es, que tu humildad ella misma te declara: porque ésta, comó los astros, más luz en las sombras guarda.

\section{LXXVIII - DAVID UNGIDO}

Presente está ya David; unge, ó propheta, su frente, porque Dios mismo al menor de todos elige i quiere. Luego estatura, linage, riquezas, ánimo fuerte nada hacen, que sólo Dios es quien el cetro concede.

38. I Samuel II, IV. Los hijos del sacerdote Helí se apropian indebidamente de las ofrendas y cometen otros abusos de autoridad. Los israelitas son derrotados, y capturada el arca de la Alianza; mueren además los hijos de Helí. Este, al saberlo, cae de su silla y muere desnucado.

39. I Samuel IX, X. Saúl sale en busca de las burras de su padre, que se hạn perdido, y se reúne con Samuel, que lo consagra rey.

40. Falta la palabra en el ms.

41. I Samuel X.

42. I Samuel XV. 


\section{LXXIX - MATA A GOLIATH}

Antes lo avía postrado mi honda con pequeña piedra; después con su misma espada su cerviz cortada queda. Assí murió Goliath; gigantes soberbios teman, que el cielo tiene de rayos aún más poderosas piedras.

\section{LXXX - DESPEDIDA DE JONATHÁS Y DAVID ${ }^{43}$}

Ia conoce Jonathás

de su padre ánimo i furias,

i la saeta arrojada avisa a David la fuga.

Por los últimos abrazos

las almas se entregan mutuas;

assí el verdadero amigo

dos corazones aduna.

$15 \mathrm{v}$.

\section{LXXXI - DA EL SACERDOTE LOS PANISS DEL ALTAR A DAVID ${ }^{4+}$}

Da los consagrados panes, sustento a David hambriento, el sacerdote, i después tu espada, ó Goliath sobervio. La misma espada le guarda con que antes pudo ser muerto. Aprende: aun del más contrario logran la salud los buenos.
LXXXII - ABIGAIL +5

Abigail, para aplacar de David la justa ira, por su indiscreto marido lleva sus dones rendida. Si es de la muger cabeza el varón, prodigio es viva baxo una necia cabeza esta muger entendida.

\section{LXXXIII - DAVID QUITA LA LANZA Y LA COPA A SAÚL}

David, que la vida pudo quitar a Saúl dormido, la lanza sólo i la capa fue lo que traxo consigo. ¡Ó, qué bien! Porque a un furioso se quita su azero mismo; ni con esta copa pudo apagarse su delirio.

$16 \mathrm{r}$

\section{LXXXIV - SAÚL CONSULTA $A$ L $A$ PHYTONISA ${ }^{+7}$}

La phytonisa lo llama, Samuel sale de la urna, Saúl lo adora y medroso oye su muerte futura. Aprende: si Dios no está favorable a tus fortunas en vano a Acheronte mueves: podrás ser dichoso nunca.

43. I Samuel XX. Saúl envidia los éxitos militares de David e intenta repetidas veces matarlo. David decide esconderse y se pone de acuerdo con Jonatán, hijo de Saúl, su amigo, para conocer los designios del rey. Pactan ambos que Jonatán lanzará flechas y que, según las palabras que dirija al criado encargado de recogerlas, David, escondido, entenderá si debe huir para salvarse. Así es; ambos amigos se despiden llorando y abrazándose.

44. I Samuel XXI. David, huido, obtiene del sacerdote Ajimelec panes consagrados a Yahvé y la espada de Goliath, depositada como trofeo.

45. I Samuel XXV. David pide a Nabal alimento para sus hombres, pero éste se niega. David marcha contra él; enterada Abigail, esposa de Nabal, detiene la venganza de David saliendo a su encuentro con presentes.

46. I Samuel XXVI.

47. I Samuel XXVIII. Saúl, al no responder Yahvé a sus plegarias, ordena a la pitonisa de Endor que convoque al espectro de Samuel, que le predice la ruina de su casa. 


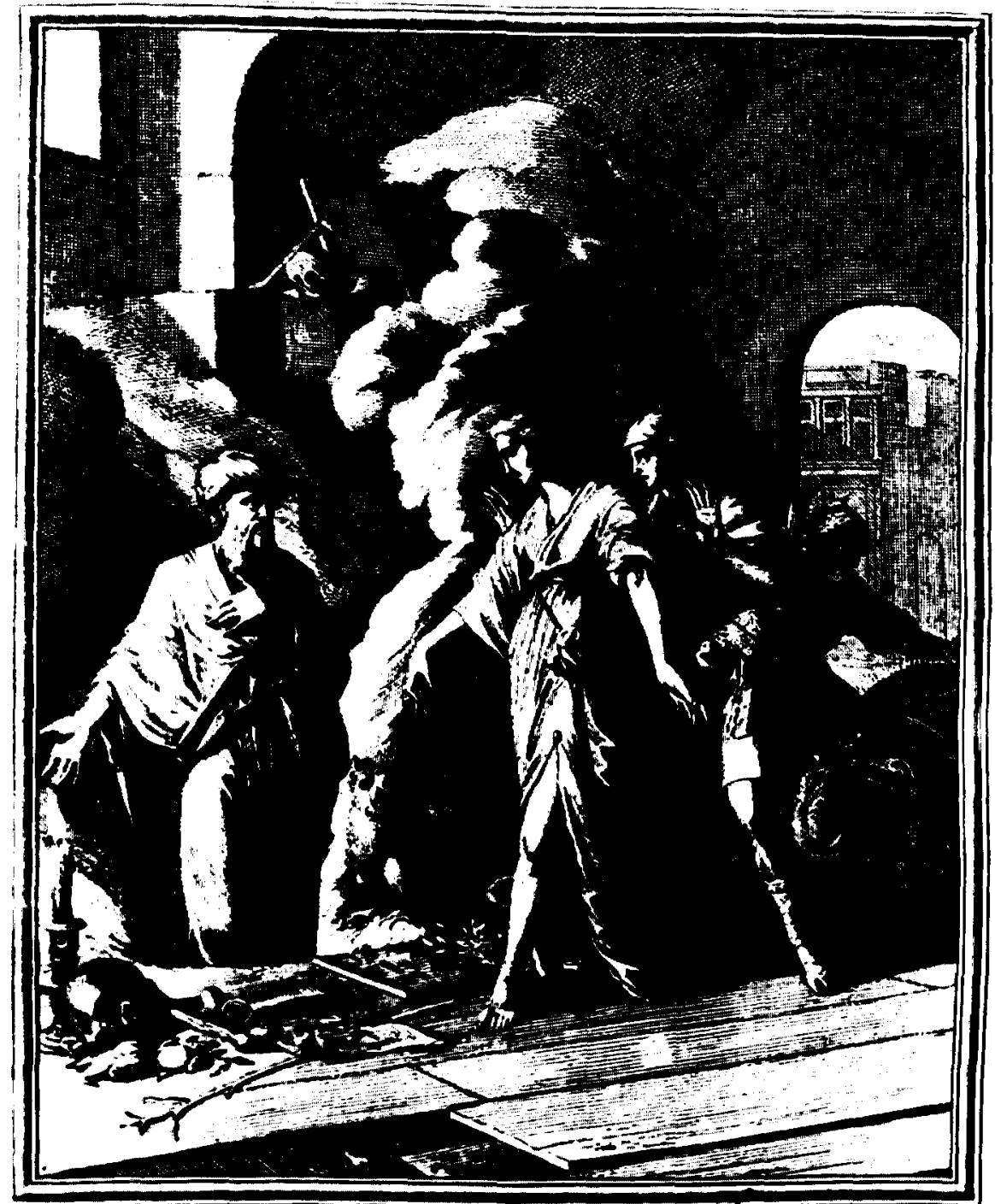

mintent

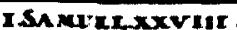

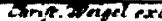

Pythoulita vurat, Samuel fere exigit urma,

Saul cultt hunc, audit cras noriere. tronesus.

Dices tors vons labces onifi Numes amicum,

Folix efse nequis, frustira Acheronta muves.

Sit icre zaubert eins. und famuel erjicheinet.

$\therefore i$ inal Ferchret den . und hört die jojtyom Tod.

S.rn hi.r sos sitt jich nicht mit deinem wunfeh yerithat,

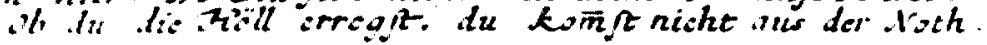

Saúl consulta a la phytonisa 
LXXXV - MUERTE DE SAÚL

Vencido Saúl i de dardos por todas partes herido, con su mismo azero, echado sobre él, se mata a sí mismo. ¿Quién no teme contra sí la ira de Dios ofendido, que hace que el culpado sea ministro de su castigo?

\section{LXXXVI - DAVID MANDA DAR MUERTE AL QUE LE PRESENTA LA DIADEMA DE SAÚL}

Asombrado ve David el brazalete y diadema de Saúl, y manda al punto que aquel que los traxo muera. $O$, con cuánta razón priba de la vida al que le alegra la muerte de rey; que assí su vida misma conserva.

16 v.

\section{LXXXVII - DA MUERTE A EL QUE TRAHE LA CABEZA DE ISBOSETH ${ }^{48}$}

A estos dos que de Isboseth la cabeza te presentan al punto, ó rey justo, quieres que al filo de azero mueran. ¿Si el engaño y asechanzas muchas más vezes tubieran aqueste premio, el palacio qué seguro lugar fuera!

\section{LXXXVIII - DAVID LIEVA EL ARCA EN TRIUMPHO}

La sagrada arca del pacto con solemne triumpho llevan; titubea, i al caerse muere $\mathrm{Oza}^{49}$, que va a tenerla.

Oza muere; luego el impio que destruie, que desprezia de Dios los templos i altares, ¡ó, qué castigo no espera!

\section{LXXXIX - NATHÁN A DAVID ${ }^{50}$}

En secreto sus delitos

Nathán a David propone; óyele el rey, se arrepiente y sus errores conoce. $\mathrm{Al}$ instante que sus culpas llora, el perdón de Dios oye; el serio llanto de un rey, ¡ó, cuánta efficacia esconde!

$17 \mathrm{r}$.

\section{XC - PERDONA A ABSALÓN EL FRATRICIDIO}

Ó fratricida Absalón, el perdón paterno debes a los ruegos que por ti la muger astuta ofrece. Admirable es el poder de la lengua en las mugeres; quando lo que ha de hablar sabe mill prodigios hacer suele.

48. En el ms. dice "Saúl» por error. II Samuel II, IV. Isboseth, hijo de Saúl, es proclamado rey a la muerte de su padre. Dos jefes de bandidos lo asesinan y llevan su cabeza a David, que manda ejecutarlos.

49. II Samuel VI. Conducida el arca en un carro, al tocarla Oza por temor a que caiga, Jahvé lo fulmina.

50. II Samuel XI, XII. Reproches del profeta Natán a David por haber hecho morir a Urías para tomar a su mujer Betsabé. 
XCI - SEMEI LO APEDREA ${ }^{51}$

Maldiciones i peñascos el cruel Semei arroxa contra su rey fugitivo, i el rei su castigo estorba.

Si el piadoso corazón de Dios ofensas perdona, ¿quién negará que este rey según su corazón obra?

\section{XCII - MUERTE DE ABSALÓN}

Traidor fue a su padre el hijo que está pendiente del árbol sirviéndole aora el cabello que antes de adorno, de lazo. Vencedor Joab, tres lanzas contra su pecho ha vibrado, porque un corazón tan duro con una no tubo harto.

$17 \mathrm{v}$.

\section{XCIII - JOAB TRAIDORAMENTE MATA A AMASA ${ }^{52}$}

La diestra la barba prende, fingen ósculos los labios, la isquierda le ase, y de Amasa el corazón hiere osado.

Assí destruió Joab su competidor bizarro.

Este arte aún dura: del mundo huie los blandos alhagos.

\section{XCIV - DERRAMA DAVID EL AGUA QUE COSTÓ MUCHOS PELIGROS ${ }^{53}$}

El rey, derramando el vaso, sacrifica a Dios el agua que tanto peligro cuesta, ni la sed con ella apaga.
Si aora los poderosos assí su sed toleraran, no se hallara tanta sangre en el mundo derramada.

\section{XCV - JUIZIO DE SALOMÓN}

Quando el rey manda que el hierro la dudosa prole parta, a su verdadera madre al punto el amor declara. Causó temor en el pueblo al advertir ciencia tanta; digno es sin duda de amor el rey que tal miedo causa.

$18 \mathrm{r}$.

XCVI - SALOMÓN EDIFICA EL TEMPLO

Aquel rey respecto a quien ni hủvo ni avrá otro más sabio, digno del inmenso Dios un templo ha edificado. Pero el corazón, de Dios templo, al amor ha entregado; i assí tan poco ha de hallarse necio que pueda igualarlo.

\section{XCVII - ACHÍAS A JEROBOAM LE DA LOS PEDAZOS DE SU CAPA ${ }^{54}$}

Quantos pedazos Ahías

te da de su rota capa, el mismo otras tantas tribus, ó Jeroboam, te encarga. Siendo la capa del pueblo symbolo, aprended, monarcas, aquel que agrava los pueblos sus hombros mismos agrava.

51. II Samuel XVI. Semei, pariente de Saúl, apedrea a David cuando éste se enfrenta a la rebelión de Absalón. David impide el castigo de Semei.

52. II Samuel XX.

53. II Samuel XXIII. Tres hombres traen, con riesgo de sus vidas, agua de la cisterna de Belén, en poder de los filisteos. David hace con ella una libación a Yahvé por parecerle frívolo beberla.

54 y 55. I Reyes XI, XII. El profeta Ajías encuentra a Jeroboam y parte su manto en doce 


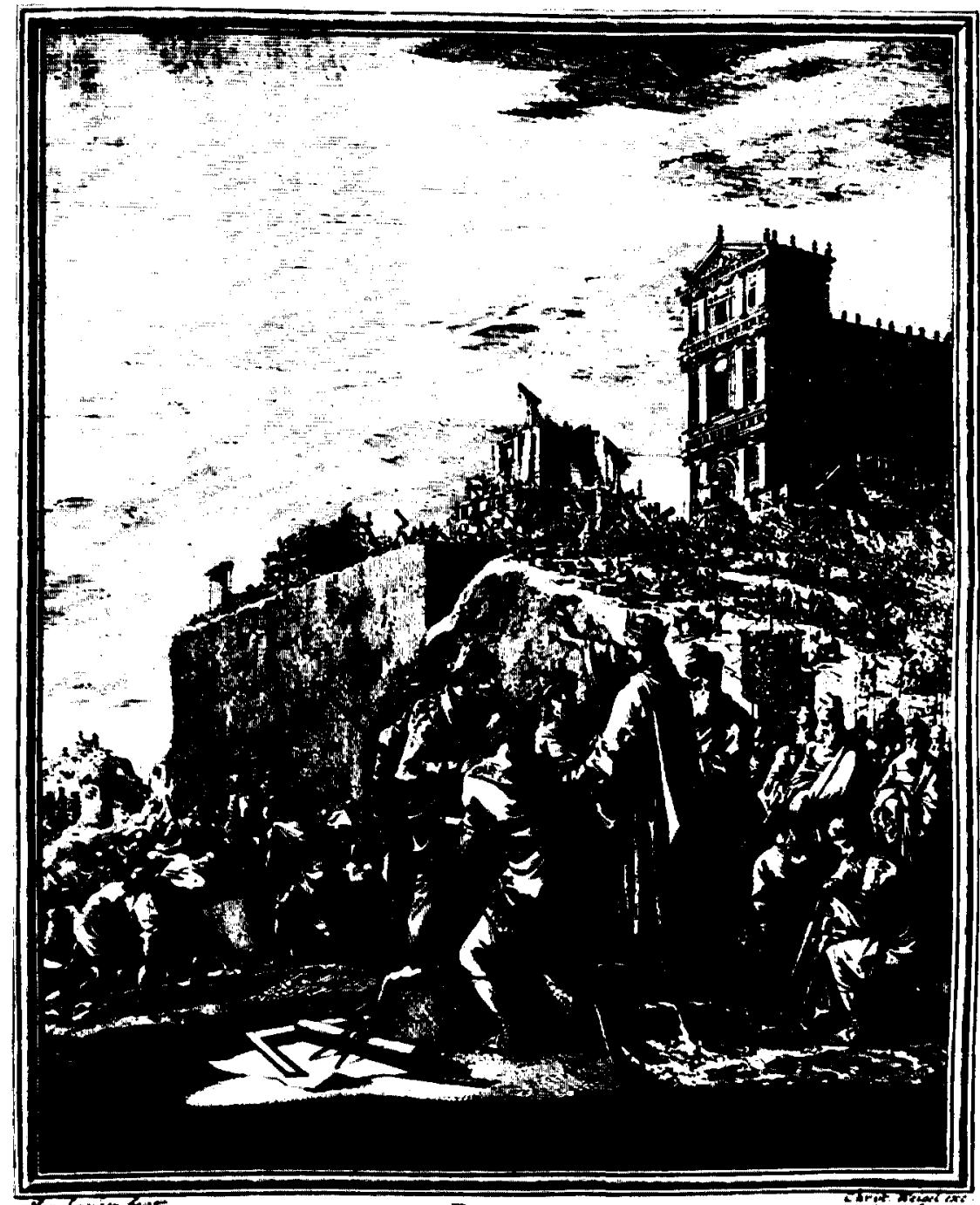

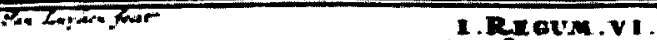

Quo nec erat. mer evit fapientior allus. in orbe. Vumine Kex dienam roudidit iste Jommu

Numinos at tempilium Crprio cor reatio Amon Sic. etiane tacunou inon habet ille parew

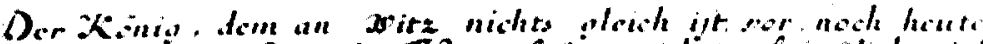

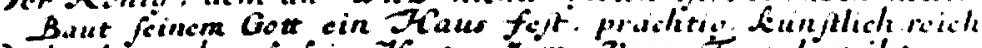

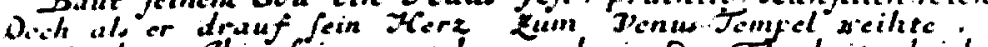
jo thuts Thin Geiner mehr auch in Der Therheit yleich. 


\section{XCVIII - SEPARACIÓN DE LAS DIEZ TRIBUS 55}

El yugo duro que el rey tyrano imponer pretende en común mutín diez tribus sacudir tratan rebeldes. Assí sucede que quando príncipe avaro les quiere sacar con graves tributos, riquezas y pueblos pierde ${ }^{56}$.

$18 \mathrm{v}$.

\section{XCIX - IDOLATRÍA DE JEROBOAM}

Rompe el ara, la ceniza se cae, del rey se entorpece la mano, y del sacerdote con ruegos a sanar vuelve ${ }^{57}$. Mas Jeroboam con tantas señales no se convierte, porque ignorar sus errores es el error de los reyes.

\section{C - UN LEÓN MATA A UN PROFETA QUE SE DESVIÓ DE SU CAMINO DIA DE AYUNO ${ }^{58}$}

A el que el prescripto camino muda, el aiuno quebranta, a este profeta un león con sañudo diente mata. Nosotros, porque quebramos de Dios la ley vezes tantas, por esso un hombre para otro es lobo en mutua venganza.

\section{CI - A JEROBOAM CONOCE UN CIEGO 59}

Aunque en vil trage vestido

a Jeroboam conoce

un ciego, y de su familia

la fatal ruina oye;

luego se da aquella luz

con la que aun los ciegos noten

los más ocultos delitos

que hasta los reyes esconden.

$19 \mathrm{r}$.

\section{CII - A ELÍAS LE TRAE UN CUERVO LA COMIDA}

El pan i la carne un cuervo, Elías, a ti te trae, i con tal comida alivia, ó gran profeta, tu hambre.

Nadie niegue que milagros cuesta a Dios alimentarte, pues quien te da la comida de hurtos sólo vivir sabe.

\section{CIII - ELÍAS PIDE A LA MUGER LE HAGA UNA TORTA ${ }^{60}$}

Ve presto, muger, y prompta llévale a aquel gran propheta lo que para ti i tu hijo sería la última cena. Después se llenará tu arca porque assí Dios mismo premia las dádivas que en sus siervos aver tomado confiessa.

pedazos, dando diez a éste, lo que indica que en el futuro, como castigo por la idolatría de Salomón, el reino será dividido, como ocurre en el reinado de Roboam, a quien sólo obedecen las tribus de Benjamín y Judá.

56. «quiere» en el ms., por error.

57. I Reyes XIII. Un profeta predice, cuando Jeroboam sacrifica en el altar de Bétel, que éste se quebrará, lo que ocurre al mismo tiempo que queda paralizado el brazo con el que el rey da la orden de prender al profeta.

58. I Reyes XIII.

59. I Reyes XIV. Se trata del profeta Ajías, ciego por la vejez. La mujer de Jeroboam va a visitarlo disfrazada, pero el profeta la reconoce y predice la ruina de su marido y de su casa.

60 y 61 . I Reyes XVII. 


\section{CIV - ELÍAS RESUCITA EL HIJO DE LA DICHA MUGER ${ }^{61}$}

Quando aplicando sus miembros

los del muchacho calienta, ¿no delinea una cruz

extendida fiel profeta?

A Christo en la cruz pendiente

esta imagen representa;

con ésta murió la muerte

i volvió la vida nuestra.

$19 \mathrm{v}$.

\section{CV - ABDÍAS SOCORRE A LOS PROFETAS ${ }^{62}$}

Para escapar de las furias

de su rey, a los profetas

en una cueva los guarda

y sustenta con su hacienda.

¿Quién es éste? Es el que Abdías

se llama; que el que professa

servir a Dios, a sus siervos

también en servir se emplea.

\section{CVI - SACRIFICIO DE ELÍAS ACEPTADO ${ }^{63}$}

En vano los de Baal

con sus clamores desean;

el fuego del cielo baxa

al punto que Elías ruega.

Con él la víctima, el ara

i aun hasta el agua se quema,

i con esta misma luz

que es nada Baal se muestra.

\section{CVII - EL ÁNGEL LLEVA PAN Y AGUA A ELÍAS}

Tomados el pan y el agua, mandan que vaia el profeta

lexos hasta los collados

donde el Monte Horeb se ostenta.
Aprende: el aiuno da

fuerza al alma; si deseas

la cumbre de las virtudes,

pisar la gula es la senda.

$20 \mathrm{r}$.

CVIII - JEZABEL CONTRA NABOTH ${ }^{64}$

De Jezabel los perjuros

astutamente fallaçes

te pierden assí, ó Naboth, infeliz i miserable.

¿Qué tempestades de ierros

la ira femenil no trae

quando contra el inocente

fulmina granizos tales!

\section{CIX - MUERTE Y CASTIGO DE ACAB ${ }^{65}$}

El soldado sin destino

dispara, y Dios la saeta

para vengarse, ó Achab, contra tu pecho endereza.

Ia antes le avía señalado

su impiedad con negra seña;

mui de intento pareció

golpe que en lo negro acierta.

\section{CX - FUIEGO DEL CIELO CONTRA LOS QUE PERSIGUEN A ELIAAS ${ }^{66}$}

Cae el capitán al fuego que Elías del cielo trae, $y$ los soldados con él en cenizas se deshacen. Temed, capitanes, reyes, al que os predica verdades, que en lugar de lanzas, rayos el Olympo arroxar sabe.

\section{2 y 63. I Reyes XVIII.}

64. I Reyes XXI. El rey Acab quiere comprar la viña que Nabot posee junto a su palacio, pero éste se niega a vender. La esposa de Acab, Jezabel, urde la muerte de Nabot.

65. I Reyes XXII.

66. II Reyes I. Los cincuenta hombres de Ocozías. 
CXI - ELIAS ARREBATADO AL CIELO ${ }^{67}$

Viendo al cielo arrebatado

tu maestro, ó Eliseo,

la capa que se le cae

tomas como grande premio.

Con esta capa en que estubo

el propheta todo fuego,

nunca en el amor de Dios

podrá reffriarse el pecho.

\section{CXII - ELISEO ENDULZA LAS AGUAS ${ }^{68}$}

Mira: el sagrado propheta, ya que tantas muertes hacen, vuelve, mesclándoles sal, essas aguas saludables.

La sal del doctor, el agua del pueblo es copia elegante. Aprende: al pueblo los dotos fuerza y salud han de darle.

\section{CXIII - MATA UN OSO LOS MUCHACHOS PORQUE SE BURLAVAN DE UN PROPHETA CALVO ${ }^{69}$}

¿Por qué contra los muchachos tan cruel verdugo se apresta? Porque assí, ¡ó propheta calvo!, se burlan de tu cabeza. Como esta fiera sus hijos forma, el hombre los desprezia; por eso acaso castigan el padre i hijos con ella.

$21 \mathrm{r}$.

\section{CXIV - ELISEO ANUNCIA LA VICTORIA A LOS REYES 70}

Quando amedrenta a tres reyes

de la batalla el suceso

se hacen piadosos, buscando, grande Eliseo, tus ruegos.
Tú ofreces, porque lo anuncia Dios, vencedores tropheos: assí la piedad, a todos útil, aiuda el esfuerzo.

\section{CXV - ELISEO SOCORRE A LA VIUDA 71}

Assí el óleo de la viuda piadoso Elías aumenta con ruegos, porque a sus hijos los redime i alimenta.

Aprende que si el amado de Dios sus manos eleva, para protegerte tiene mui poderosa influencia.

\section{CXVI - ELISEO ENTREGA VIVO EL HIJO A LA MADRE ${ }^{72}$}

La muger salta de gozo viendo a su hijo, desea decir a voces: ;ó, quánta es tu piedad, ó profeta! Mi hijo antes con tu favor a nueva vida se alienta; aora yo, que el corazón de que carecí me entregas.

$21 \mathrm{v}$.

\section{CXVII - ELISEO ENMIENDA LAS COMIDAS MORTÍFERAS $^{73}$}

Las mortíferas comidas de la olla Eliseo enmienda; después con nuevo prodigio los panes i el vino aumenta. $A l$ varón de Dios aclama i adora bien satisfecha la turba. Quita la hambre si agradar los tuios piensas.

67 y 68. II Reyes II.

69. II Reyes II. Se trata igualmente de Eliseo.

70. II Reyes III. Se trata de los reyes de Israel, Judá y Edom coaligados contra Moab.

71. II Reyes IV.

72 y 73. II Reyes IV. El ms. dice «Elías». 
CXVIII - NAAMÁN SE BAÑA EN EL JORDÁN ${ }^{74}$

Las corrientes del Jordán

de Naamán limpian la lepra, que pudo aver en el río del juicio tanta fuerza.

En la cruz el corazón

del juez divino agua ostenta;

acercaos, pecadores,

que este licor más penetra.

\section{CXIX - HUIE EL EXERCITO QUE SITIABA A SAMARIA ${ }^{75}$}

Assombrado el syro huie, todos los reales dexa, i con esto de Samaria la cruel hambre se quita.

$O$ afligidos, confiad, si la razón os alienta, que os dará al fin Dios socorro i el enemigo riquezas.

$22 \mathrm{r}$.

\section{CXX - CASTIGO DE JEZABEL}

Quando a sus pies los caballos

a Jezabel despedazan, vianda i bebida los perros en su carne i sangre hallan. Con razón en tales vientres el sepulchro se prepara a la que fue en lo lascivo carne, y fiera en lo tyrana.

\section{CXXI - EL MUERTO EN EL SEPULCRO DE ELISEO RESUCITA ${ }^{76}$}

El muerto que en el sepulcro del grande Eliseo entierran al punto a recobrar vuelve nueva vida que le alienta.
Si aun sepultados los huesos pudieron dar vida nueva ${ }^{77}$ del justo, ¿acaso quando hable obrará menos la diestra?

\section{CXXII - EZECHÍAS MANDA ROMPER LOS ÍDOLOS}

Rompe, Ezechías, la sierpe

i simulacros nefandos si acaso quieres que sea tu dominio afortunado.

El rey que es piadoso, el que contra Dios no sufre ossados, éste tampoco tendrá que recelar sus contrarios.

$22 \mathrm{v}$.

\section{CXXIII - SENACHERIB EN HUÍDA}

Con este castigo Dios multa al assyrio tyrano; assí a su Jerusalem libra del fiero contrario. Aún todavía en el cielo quedan ángeles y rayos; tema, si es que queda algún Senacherib que sea osado.

\section{CXXIV - MF YGUA LA SOMBRA DEL KiLLOX ${ }^{78}$}

La vida parece sombra, i noche la sombra larga; quanto más larga es la vida tanto hacia la muerte anda. Luego con razón el rey pide la sombra menguada porque de allí bien infiere que assí su vida se alarga.

74. II Reyes V. Namán, jefe del ejército sirio, se baña siete veces en el Jordán por consejo de Eliseo.

75. II Reyes VII.

76. II Reyes XIII.

77. «La vida nueva" en el ms.

78. II Reyes XX. Isaías invoca a Yahvé, que hace retroceder diez grados la sombra del re- 


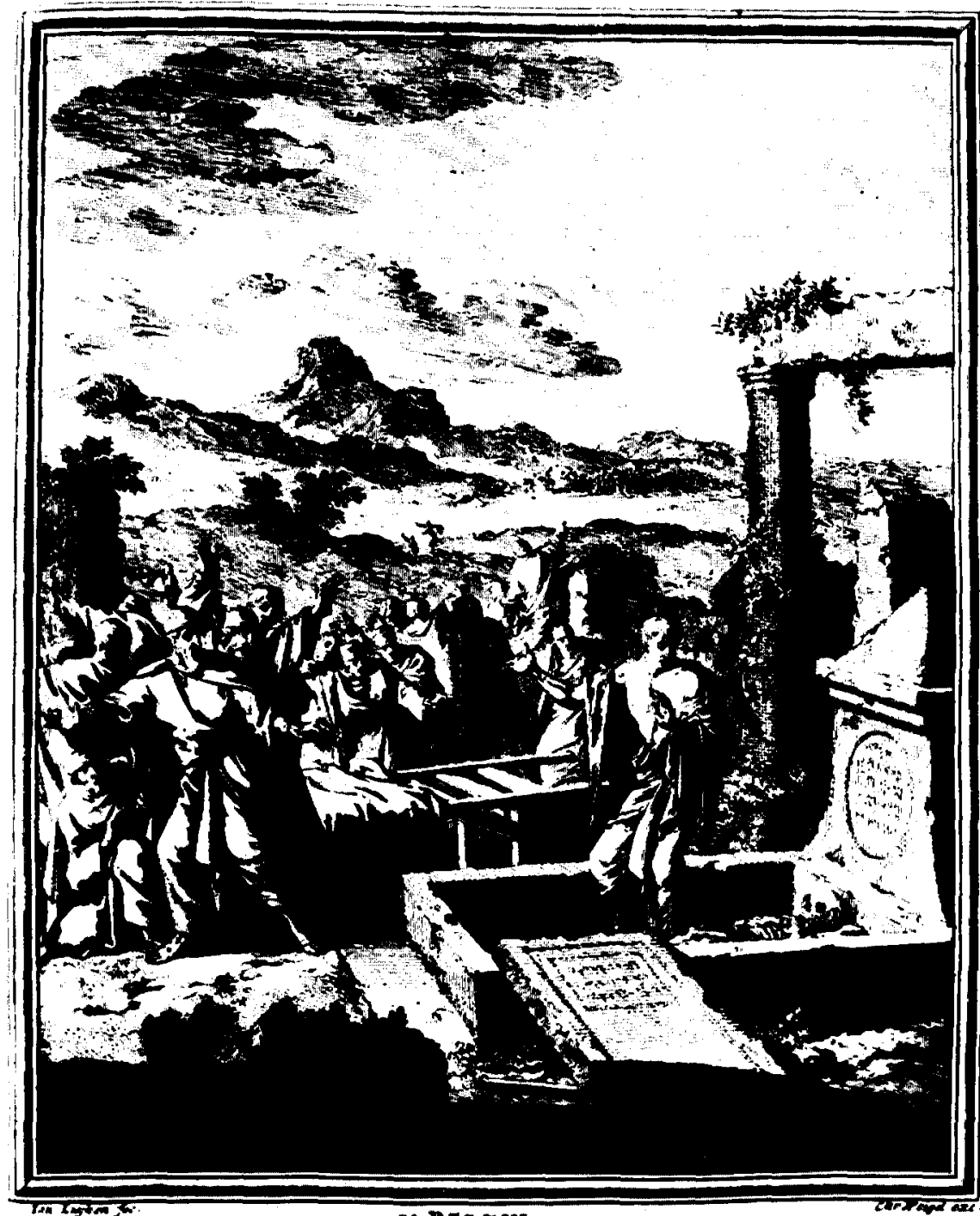

Qui fuit in tunilum magni proiectus Flisa, Mox recipit vitim morturi inde fuam. ofa queunt adferre. licet tumulata, falutem. An inenus os Insti quando loquetur aget :

Di. Tole tithet auf zu einem neuen Da man ihn in Las frat Elifa zparf hinein. :asn tide Beine so das jeben wieder aeben. sollt des Gerechten liund zon mindern $x$ rifjiten jitin.

Resucita el muerto en el sepulcro de Eliseo 
CXXV - EL PROFETA HOLDA

ANUNCIA LA RUINA

DE JERUSALEM ${ }^{79}$

Holda, profeta funesto, de Jerusalem avisa la ruina a los legados, muerte cercana a Josias. Para que no sólo guarden en la arca la ley divina los hijos como sus padres, debió la vara advertida.

$23 \mathrm{r}$.

\section{CXXVI - CASTIGO DE LA PESTE QUANDO DAVID ${ }^{80}$}

¡Quánto al ángel con la espada vengadora David teme!

Porque a su pueblo destruie con la peste que le hiere.

Llora el rey, gime, i los yerros de su hinchada qüenta advierte, que disminuió los hombres que multiplicar pretende.

\section{CXXVII - HIERE EL ROSTRO EL FALSO PROFETA AL PROFETA DE DIOS ${ }^{81}$}

De dos reyes en presencia i ministros de dos reyes del sacro profeta el rostro el falso profeta hiere. Assí los impíos palacios que pagar mentira suelen con menosprecios reciben al que verdades ofrece.

\section{CXXVIII - OBED AMENAZA A LOS VICTORIOSOS ${ }^{82}$}

Legado de Dios airado, Obed temores impone a los victoriosos, que eran mui crueles i feroces.

¿Quiera Dios que en nuestro tiempo igual profeta se logre que de los que a Christo siguerı temple guerrass i rencores!

$23 \mathrm{v}$.

CXXIX - SALIDA DE LA CAPTIVIDAD DE BABILONIA

¡Ó, qué ligero y qué alegre, el iugo babilón suelto, vuelve a sus antiguas casas de Jerusalem el pueblo! Destierro es el mundo, cárcel el cuerpo, la patria el cielo; ¿por qué, pues, la muerte temes que te libra de este riesgo?

\section{CXXX - LOS ABRAHAMITAS LABRAN CHOZAS}

Palmas los Abrahamitas

llevan, i gustosos labran, dexándose la ciudad, las chozas con verdes ramas. Assí la pacienzia nuestra en el mundo labra palmas, para que feliz de allí se eleve al cielo la casa.

loj, señal pedida por el rey Ezequías.

79. II Reyes XXII. Yahvé ordena la restauración del templo, y es hallado el Deuteronomio, que da lugar a la reforma religiosa de Josías. La profetisa Holda anuncia los males que vendrán de la no observancia de su contenido.

80. I Paralipómenos XXI; II Samuel XXIV; Exodo XXX. El censo que David manda hacer origina la ira de Yahvé y el castigo de la peste, por no haberse realizado el tributo sagrado que el censo conlleva.

81. II Paralipómenos XVIII; I Reyes XXII. Miqueas pretende disuadir a los reyes Acab y Josafat de atacar Siria, y es abofeteado por Sedecías. Ver estrofa CIX.

82. II Paralipómenos XXVIII. 


\section{CXXXI - REEDIFICACIÓN DE JERUSALEM}

Una mano lleva cal, la otra govierna la espada; se pelea y se edifica, assí la obra se levanta.

Con razón aun el soldado a Dios le fabrica casa, que de la ciudad en este lugar ha de estar de guarda.

$24 \mathrm{r}$.

\section{CXXXII - HONORES A MARDOCHEO ${ }^{83}$}

Assí el soberbio Amán sirve a tu honor, ó Mardocheo, i de tu mérito insigne donde quiera es pregonero.

A él, porque baxo sus pies te quiso tener primero, una horca le ha de dar lugar que merece excelso.

\section{CXXXIII - JOB, QUE PIERDE TODOS SUS BIENES}

Uno que faltó el ganado, otro los hijos, la casa otro avisa, i Job a Dios con ánimo i boca alaba. Él lo dio, dice, i es suio todo lo que cobrar trata; io nada soi, i assí a mí sólo pertenece nada.

\section{CXXXIV - JOB EN EL MULADAR}

Después de todas tus llagas y de tus falsos amigos llega por fin tu muger imbiada del Lago Stygio ${ }^{84}$.
Ten ánimo, ó Job, recobra todos tus antiguos bríos, que de una muger la lengua vence quanto malo ha avido.

$24 \mathrm{v}$.

\section{CXXXV - JOB RESTITUIDO A SUS RIQUEZAS DOBLADAS}

Hijos, esclavos y ovejas i todo, en una palabra, lo que perdió, Dios a Job da con doblada ganancia. $\mathrm{Ni}$ es de admirar el que assí floresca en edad tan larga quien con su invicta pacienzia se vinculó rosas tantas.

\section{CXXXVI - JEREMÍAS EXPLICA LA DESGRACIA DE JERUSALEM ARROJANDO UNA OLLA AL SUELO ${ }^{85}$}

La olla, que arroxada al suelo con la mano se quebranta de Jeremías, explica, Jerusalem, tu desgracia. Con el lodo de las culpas dura al calor de la Gracia, de Dios serás esparcida por enemigas moradas.

\section{CXXXVII - QUEMA EL REY LAS AMENAZAS QUE ESCRIVE JEREMÍAS ${ }^{86}$}

Apenas la lee, quema el rey la carta traída, porque allí de sus delitos i su castigo le avisan.

83. Esther XI, XII, I-III, VI, VII. Mardoqueo, funcionario de Asuero, se gana la enemistad de Amán. El rey toma por mujer a Esther, pariente de Mardoqueo. Cuando Amán logra un decreto de exterminio de los judíos, Esther lo acusa ante el rey; es condenado a muerte y revocado el decreto.

84. Job II. Su mujer lo incita a maldecir a Dios.

85. Jeremías XIX.

86. Jeremías XXXVI. 
Porque a quien las lenguas buenas

feroz tyrano apellidan

nada debe temer más

que las plumas que lo escrivan.

$25 \mathrm{r}$.

\section{CXXXVIII - JEREMÍAS ARROJADO EN}

UN POZO ${ }^{87}$

De la cueva en que el furor

impío de los que mandan

hizo arroxar al propheta, mandándolo el rey le sacan.

Que huiga vecinos peligros

entonces al rey encarga,

que no es razón que peligre

rey que a los buenos ampara.

\section{CXXXIX - CAPTIVIDAD DE BABILONIA}

Assí Salem se destruie, assí el cruel enemigo riqueza del templo sancto se lleva con los cautivos. Con razón perdió el hebreo su templo que tanto quiso, pues antes con sus ofensas a su Dios avía perdido.

\section{CXL - LOS NIÑOS DEL HORNO. DE BABILONIA ${ }^{88}$}

La estatua rel rey assirio mira, i a un tiempo las llamas ardientes que a los tres niños son la pena preparada. Assí es que quando los reyes divinos honores anxian, entonces el innocente es materia de las llamas.
$25 \mathrm{v}$.

\section{CXLI - CENA DE BALTHAZAR}

Teme el rey, que de sagrados vasos bebe los licores, a las ignoradas cifras que una sombra le propone. ¿La sombra assí assombrar puede? Lo que pudiera conoce la mano de Dios armada de rayos abrasadores.

\section{CXLII - DANIEL EN EL LAGO DE LOS LEONES}

Aunque más hambrientos ante Daniel los leones se hallen, amansados se le rinden y dissimulan la hambre. A éste quiso verle muerto la invidia de los magnates; luego a los buenos sólo el palacio puede dañarles.

CXLIII - JONÁS ARROJADO A EL MAR

Náutica, turba, ¿qué tardas?

Pues ya la ballena abre

la boca, arroja a Jonás

a los turbulentos mares.

Temió el decreto de Dios

en Nínive publicarle, y assí será castigado de un mudo pez en la cárzel.

$26 \mathrm{r}$.

\section{CXLIV - LA BALLENA ARROJA A JONÁS}

De Nínive poco lexos

la ballena a Jonás vierte, a quien tres días i noches sirvió de cárzel su vientre.

\section{Jeremías XXXVII, XXXVIII.}

88. Daniel III. Se trata de la estatua de Nabucodonosor divinizado. 


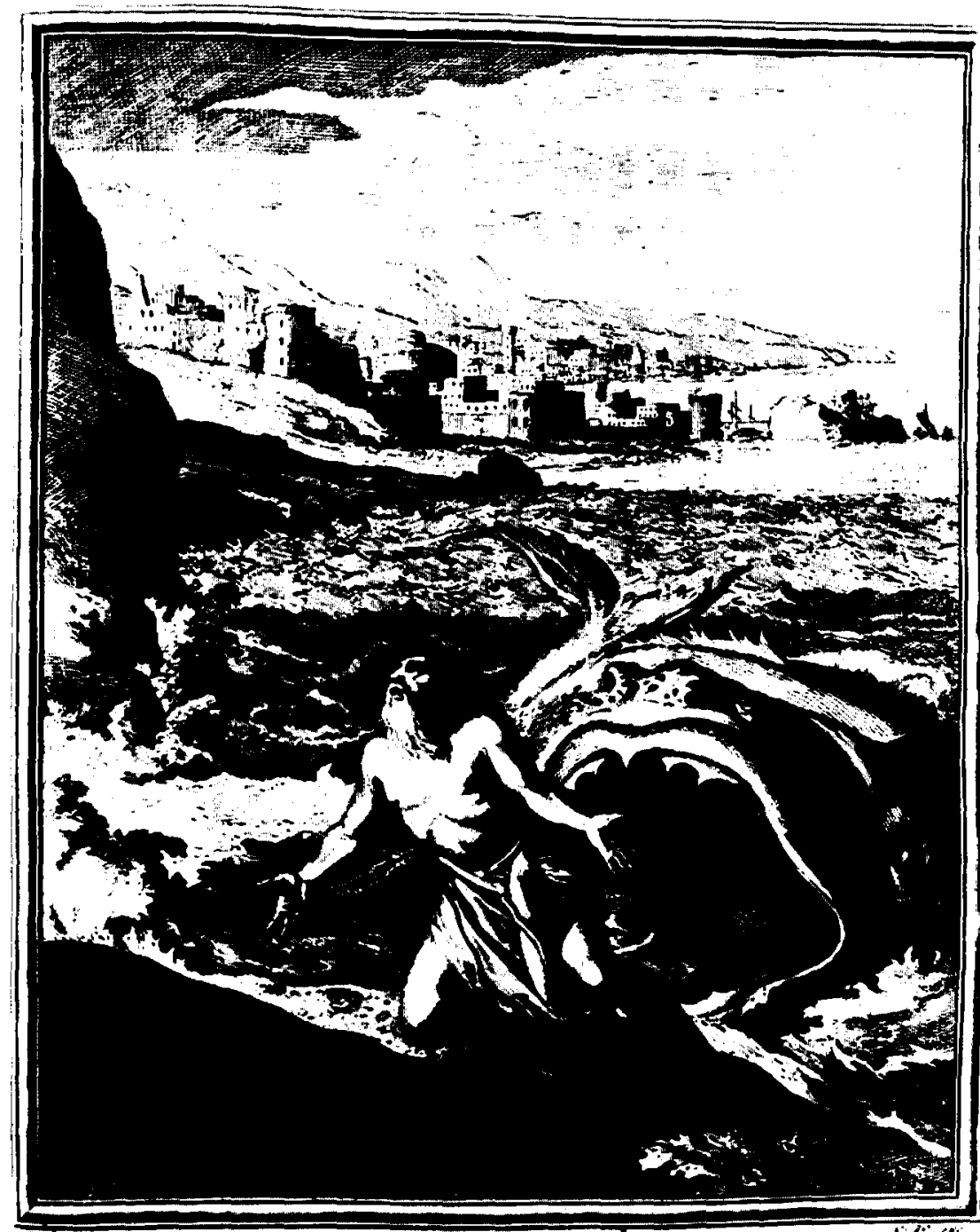

Ions. II.

Nent procul a Ninive cetus Ionom evomit urber, (iii carme terinâ nocte dieque fuit.

Dilier cito parrie Dro quocungue vocanti;

Non vis? vis illuc, quo rapieris, erit.

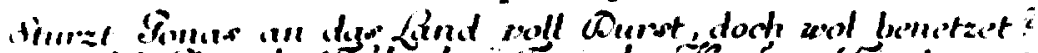

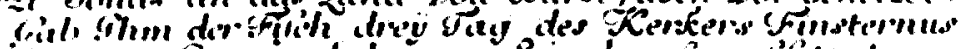

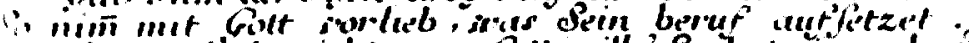

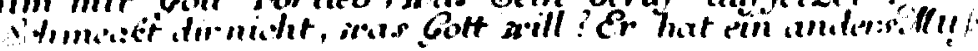

La ballena arroja a Jonás 
A obedecer presto a Dios

a donde te llama aprende.

¿No quieres? Pues avrá fuerza

que con violencia te lleve.

\section{CXLV - JONÁS ANUNCIA LA RUINA}

\section{DE NÍNIVE}

A los ninivitas Jonás

de su ciudad la ruina

anuncia, i el rey i el pueblo

con llanto a Dios apaciguan.

Perdónale, i floreciente

permanece. Aprende: libra

Dios a aquel que sus delitos

él por sí mismo castiga.

\section{CXLVI - JONÁS SIENTE NO VER DESTRUIDA A NÍNIVE}

Quando descansa a la sombra

de la floreciente yedra

siente que la destruición

de Nínive aún no se llega.

Si la ciudad permanece

que cae sú fama rezela

el propheta; ;ó, quántos hombres

la vanagloria enagena!

26 v.

\section{CXLVII - JUDITH}

La cabeza que Judith

cortó con espada ajena

mira: ia cabe en un saco,

i maior que el mundo era.

Ó sobervios, a quien Dios

aun con semexante diextra

suele castigar mill vezes,

temed la mugeril fuerza.

\section{CXLVIII - EL JOVEN TOBÍAS}

Coge i registra esse pez

i nada temas, Tobías;

su corazón huie el Diablo,

su hiel los ojos alivia.
Tantos ciegos ai aora, tantos prende la lascivia... ¡Ó, si también este pez se hallara en nuestras orillas!

\section{CXLIX - EL JOVEN TOBÍAS CURA A SU PADRE}

Apenas el joven llega, del ciego padre Tobías con la hiel los ciegos ojos unta, i la salud le aplica. El hijo que es bueno quiere del padre clara la vista; el malo es sólo el que quiere sus luzes obscurecidas.

$27 \mathrm{r}$.

\section{CL - CASTIGAN LOS ÁNGELES A HELIODORO ${ }^{89}$}

Un ángel castiga a este

Heliodoro, que imbiado a Jerusalem, intenta robar el sagrado erario. Io os aviso, no busquéis, capitanes, tales sacos, que vuestro exército todo puede destruir tal mano.

\section{CLI - MUERTE DE ANTÍOCO ${ }^{90}$}

Este rey, quando, en furor ardiendo, amenaza fuego a Jerusalem, del carro como Phaetón cae al suelo.

Enfermo muere, i a todos ahuienta su hedor violento. ¡Ó, qué sentina de vicios es el hombre que es sobervio!

\section{$151^{91}$}

$27 \mathrm{v}$. = en blanco

89. II Macabeos III. Heliodoro es enviado a requisar las riquezas del templo de Jerusalén. Un ángel a caballo y con armadura de oro lo derriba mientras otros dos lo azotan; se repone gracias a las plegarias del Sumo Sacerdote.

90. "Heliudoro" en el ms. II Macabeos IX.

91. Recuento de las estrofas hasta el final de esta primera parte. 


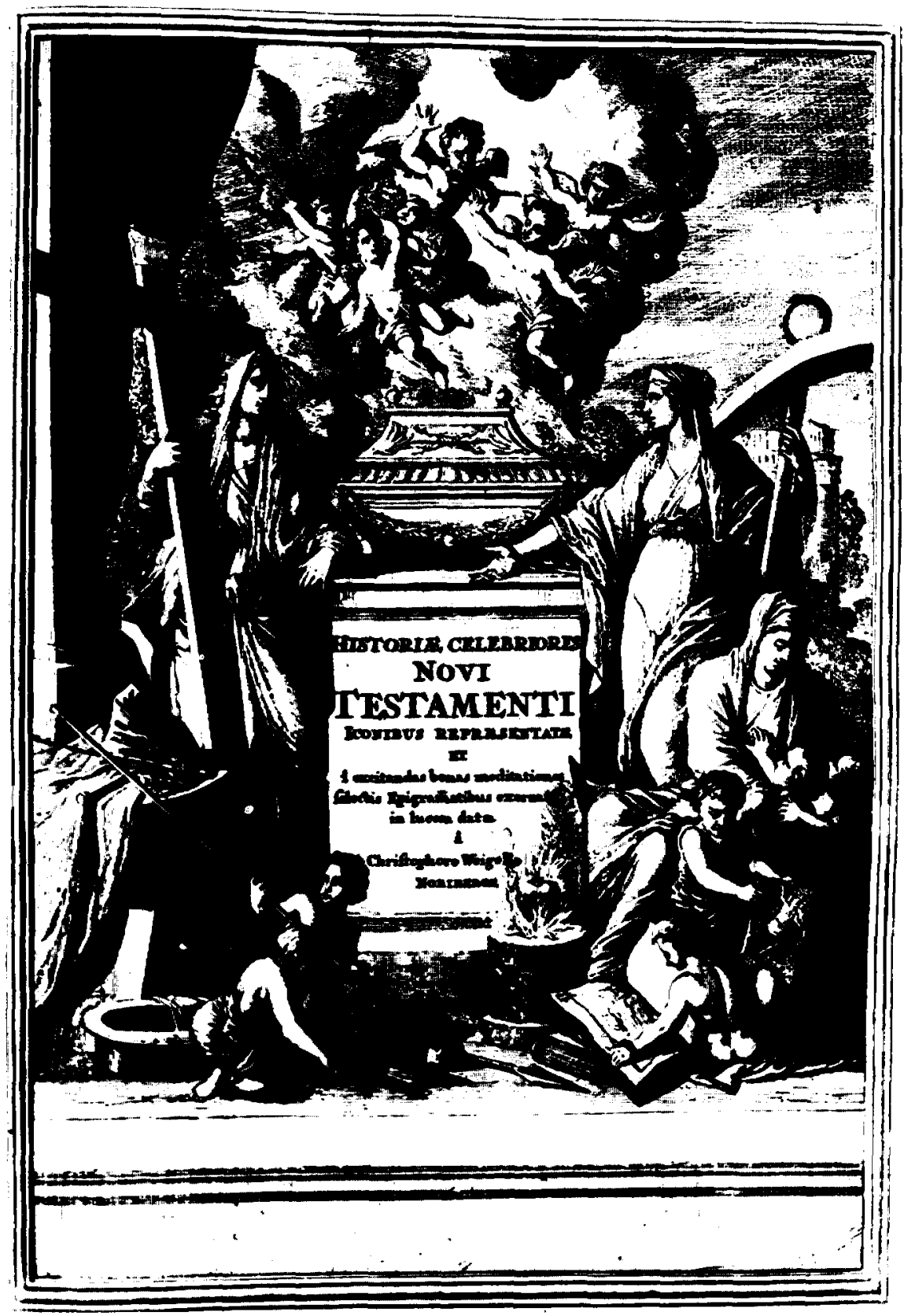


$28 \mathrm{r}$.

\author{
HISTORIAE CELEBRIORES \\ NOVI \\ TESTAMENTI \\ ICONIBVS REPRAESENTATAE \\ ET \\ ad excitandas bonas meditationes \\ selectis Epigrammatibus exornatae \\ in lucem datae \\ a \\ Chistophoro WEIGELIO \\ NORIBERGAE \\ y la tradución [sic] en verso castellano de \\ Dn. Ignacio Luzán \\ y de su mano y pluma
}

$28 \mathrm{v}$. $=$ en blanco

$29 \mathrm{r}$.

CLII - ADORACIÓN DE LOS REYES MAGOS A CHRISTO N.S.

Mira cómo ofrece dones la trinidad de los reyes, a quien una estrella guía i a Dios muestra en un pesebre. ¡Ó, si más veces siguieran la luz del cielo los reyes, cómo conocer pudieran héroes que les aprovechen! 


\section{CLIII - HUIDDA A EGIPTO}

A Dios apenas nacido llevan a Egipto en destierro, que a hacer esta huída obliga el furor de Herodes fiero. ¡Ó cruel estirpe de Herodes! Quiere éste destruir el Verbo i no puede; puede aquél, i la voz de Dios ha muerto.

\section{CLIV - PREDICACIÓN DEL BAPTISTA}

El Baptista, voz de Dios, clama. Concurrid, ó pueblos, i os enseña a preparar a Dios, que viene, los pechos. Vosotros, a quien el agua lavará, llorad, ó reos, que este agua no purifica si el llanto no va primero.

$29 \mathrm{v}$.

\section{CLV - BAUPTISMO DE CHRISTO}

Él a tus plantas, ó Christo, no se atreve aun a humillarse, i tu cabeza tú mismo al Baptista sugetaste. Él baptizó tu cabeza, a quien nada ai que se iguale, luego ni aun en esto pudo algún hombre aventajarse.

\section{CLVI - LAS TENTACIONES}

A que le tiente el maligno genio Jesús se permite; assí las armas te dexa con que puedas rebatirle. Sea tu escudo la palabra de Dios, que cuando le ciñe el pecho, el infernal genio nunca puede combatirle.

\section{CLVII - SERMÓN DE LA MONTAÑA}

Qué virtud, qué vida hacer dichosos los hombres pueda, assí lo enseñas, ó Christo, del monte en la cumbre excelsa. Tu escuela, ó Christo, es el monte. Luego el que la áspera senda rezela por los peñascos ser tu discípulo niega.

$30 \mathrm{r}$.

\section{CLVIII - EL CENTURIÓN 92}

Este centurión en una palabra le pide al Verbo Divino con voz humilde que alivie a su hijo enfermo. En la hora en que lo pide sale su hijo del lecho; assí su prompta fee hace prompto a Dios en su remedio.

\section{CLIX - CHRISTO DUERME EN LA BARCA DE SAN PEDRO ${ }^{93}$}

Los discípulos turbados turban de Jesús el sueño, claman que les dé socorro, que perece el frágil leño. Despierta, i con querer sólo apacigua olas i vientos; aprende que Dios aiuda obligado de los ruegos.

\section{CLX - ESCOJE A MATHEO}

En el lugar en que toma i qüenta dinero i premios, en éste quieres, ó Christo, que a ti te siga Matheo. El sigue a ti, que le llamas el atractivo venciendo del oro; luego esta voz te acredita Dios immenso. 


\section{CLXI - LOS DISCÍPULOS DE CHRISTO ARRANCANDO ESPIGAS EN SÁBADO ${ }^{94}$}

No murmures, que la hambre, arrancando mieses secas, los discípulos de Christo, ó phariseo, sosiegan.

A los que en luz de doctrina del orbe antorchas se muestran que se les dé el alimento ningún sábado lo veda.

\section{CLXII - CHRISTO PREDICA DESDE LA NAVE}

Ves aquí Jesús escoge por su cáthedra una nave, para enseñar de allí al pueblo con consexos saludables. Palabras de salud tiene más preciosas que el diamante, luego hasta aora nave alguna no traxo riquezas tales.

\section{CLXIII - PARÁBOLA DEL QUE COMPRA EL CAMPO DEL TESORO}

Qué prudente, dices, fue el comprador que su hacienda vendió toda i compró el campo que oculta tantas riquezas.

Si a Dios lo diera en sus pobres comprador del cielo fuera; luego el avaro sus bienes neciamente los reserva.

$31 \mathrm{r}$.

\section{CLXIV - LA DEGOLLACIÓN DEL BAPTISTA}

Con la espada de un verdugo cae a escondidas la inocente cabeza que la danzante del rey amada apetece. Ni es maravilla: el Baptista de Dios que clama se cree voz; nada el lascivo amor más que esta voz aborrece.

\section{CLXV - SAN PEDRO SE HUNDE EN} EL MAR

Luego que a Jesús conoce

Pedro, salta de la nave; camina i el mar le ofrece a su pie camino estable. Sopla el Bóreas, teme, se hunde en el mar, Jesús le vale; fluctúa el agua por que de Pedro a la fee se iguale.

\section{CLXVI - PARÁBOLA DE UN CIEGO A OTRO CIEGO GUÍA}

Un ciego a otro ciego guía i quando le guía, entrambos en un hoio se despeñan con salto precipitado. Pedid, doctores, a Dios luz que alumbre vuestros pasos; porque vuestra ruina a muchos conduce al Stigio lago.

$31 \mathrm{v}$.

\section{CLXVII - LA CANANEA ${ }^{95}$}

Mientras que la cananea clama, ruega, insta i repite no sin alabanza, a su hija logra la salud que pide. Aprende: si Dios tus ruegos luego al instante no admite, quiere que en fee i esperanza más tiempo te muestres firme.

\section{CLXVIII - CHRISTO MULTIPLICA SUS MILAGROS}

Christo está presente, huien males i stygios contrarios, anda el coxo $i$ el que fue ciego la vista ha cobrado. Fiadosa turba le admira y del Maestro sigue el lado; assi el que con beneficios instruie es de nuestro agrado.

\footnotetext{
94. Mateo XII.

95. Mateo XV.
} 


\section{CLXIX - CURA A EL ENDEMONIADO 96}

El mal huésped que afligió

al mísero en fuego i agua, éste, ó Christo, de tu voz teme i huie la efficacia.

Los discípulos resiste que en arroxarle trabajan, que por tener débil fee fuerzas bastantes les faltan.

$32 \mathrm{r}$.

\section{CLXX - CHRISTO ENSEÑA QUE LA PUERTA DEL CIELO ES ESTRECHA}

A los que hace la soberbia del mundo vanos e hinchados, este pequeño amedrente con su minuto tamaño ${ }^{97}$. La puerta del Cielo no es maior que uno de estos parvos, luego a los grandes sobervios no está abierto su palacio.

\section{CLXXI - PARÁBOLA DEL AMO QUE PERDONA A SU CRIADO, I ÉSTE NO PERDONA A SU COMPAÑERO}

El señor perdona todo, pero el criado sus deudas cobra de su compañero con el miedo i la violencia. Al que antes su compañero atormentó le atormentan también después: sé tú blando si a Dios piadoso deseas.

\section{CLXXII - CHRISTO ABRAZA A LOS NIÑOS}

Quando miras con qué amor

Jesús los niños abraza, ¡ó, si fuera yo también pequeñuelo acaso!, exclama.
Dobla la rodilla, humilla el cuello a la Deidad sacra; assí humillado a los brazos de la Deidad te preparas.

$32 \mathrm{v}$.

\section{CLXXIII - EL MOZO RICO}

El mozo rico, a quien mandas que dé a los pobres su hazienda, qué presto, ó Christo, i qué triste se retira y se amedrenta. ¡Ó, quán sin razón llamamos fortunas a las riquezas, si ellas mismas ser perfectos i felices no nos dexan!

\section{CLXXIV - LOS OPERARIOS QUE FUERON A TRABAJAR A DISTINTAS HORAS}

El que vino tarde pero bien las vides cultivó el mismo precio recive que el que de mañana entró. Dios es señor que assí paga, que da muchas veces Dios maior premio que el trabaxo, i no puede dar menor.

\section{CLXXV - CHRISTO ARROJA DEL TEMPLO A LOS VENDEDORES}

En aquel tiempo, ó Jesús, piadossísimo del templo arroxas los que su honor profanado hacía reos. Nosotros también mil vezes tus iglesias ofendemos; con razón, pues, de tu azote los castigos padecemos.

\footnotetext{
96. Mateo XVII.

97. Mateo XVIII. Alusión a los niños.
} 


\section{CLXXVI - LA VIÑA Y LOS MALOS ARRENDADORES}

Este typo del hebreo mató antes tantos prophetas, después al Hijo de Dios clavó en la cruz su fiereza. Ó christianos, no arroxéis de vuestros pechos la excelsa palabra de Dios, por que vuestro este typo no sea.

\section{CLXXVII - PARÁBOLA DEL QUE VINO AL COMBITE SIN EL VESTIDO 98}

Desnudo huésped que al real combite atrevido entraba, a lo obscuro de una cueba es llevado, el rey lo manda. Si púrpura no nos viste de la sangre derramada en la cruz, de igual tiniebla pena el abismo nos guarda.

\section{CLXXVIII - LO QUE ES DEL CÉSAR, A CESAR}

Quando al darte la moneda muestras, ó Christo, que el censo, si es del César, se dé al César, i si es de Dios a Dios mesmo, el que a tentarte venía se admiró i quedó en silencio, que en no pudiendo engañar calla la voz del hebreo.

$33 \mathrm{v}$.

\section{CLXXIX - JESUCHRISTO LLORA SOBRF GERUSALEM $^{99}$}

Mira cómo aquí en piadoso llanto Jesús se derrite quando ve i que ha de arruinarse tan grande ciudad predice.

\section{Mateo XXII.}

99. Mateo XXIV.

100. "parábolas» en el ms.

101. Mateo XXV.
Llorando a Gerusalem quiere que su llanto imite porque de Dios vengador los rayos esta agua impide.

\section{CLXXX - PARÁBOLA DE LAS VÍRGINES}

Cinco vírgines despiertas vienen, cinco se durmieron; a éstas se cierra la puerta del Cielo, a aquéllas se ha abierto.

Luego no ai otra peor pérdida que la del tiempo,

* a quien de la salvación se sigue a vezes el riesgo.

\section{CLXXXI - PARÁBOLA ${ }^{100}$ DE LOS TALENTOS}

A los que trahen ganancias el señor dones entrega, i el que el talento enterrado vuelve, pierde las riquezas. La Gracia que para el uso no aplicaste se te niega, que para el justo Dios es perder quando no grangeas ${ }^{101}$.

$34 \mathrm{r}$.

\section{CLXXXII - EL JUICIO UNIVERSAL}

De sus sepulcros los justos i reos a premios i penas obligará a presentarse al fin del Juez la trompeta. Si despreciando esta imagen todavía alguno peca, o de ojos o de mente es forzoso que caresca.

\section{CLXXXIII - OBRAS DE MISERICORDIA: DAR DE COMER AL HAMBRIENTO}

Christo tiene hambre, el pobre quiere que se la remedien, que tan unido a los pobres como esto su amor le tiene. 
Con su carne i con su sangre te alimenta tantas veces, ii tú en los pobres de Christo la hambre permitir puedes!

\section{CLXXXIV - DAR DE BEBER AL SEDIENTO}

Nada tienen los mortales que valga menos que el agua, i no obstante, dada a Dios a precio grande se paga. Da, pues, al que tiene sed el vaso con mano franca, que por él tu salvación puedes creer se te alcanza.

$34 \mathrm{v}$.

\section{CLXXXV - DAR POSADA AL PEREGRINO}

Si algún pobre peregrino a ignorada ciudad viene, de tu casa abre las puertas, ofrece i dá lo que puedes. ¿Recibes a éste? Pues quando la muerte a otro orbe te lleve, Christo te recibirá de su Padre en el alvergue.

\section{CLXXXVI - VESTIR AL DESNUDO}

Mira el desnudo, a quien urge o su suerte o su pobreza que lluvias, fríos o soles es preciso que padesca. Desnudo a Christo en la cruz. clavaron tus insolencias; razón es que en este pobre su túnica a Christo vuelvas.

\section{CLXXXVII - VISITAR LOS ENFERMOS}

El enfermo que afligido iace, pide le consuelen; hazle con tu compassión el peso que sufre, leve. A quien la enfermedad, el asco o el tedio lexos expellen, éste no puede llamarse próximo del que padece.
$35 \mathrm{r}$.

CLXXXVIII - VISITAR LOS ENCARZELADOS

En obscura cárzel llora macilento el prisionero; alivia a este miserable con tu socorro i comerzio. Si esto haces, tu alma, que ahora está en la cárzel del cuerpo, también hallará después a Dios que le dé consuelo.

\section{CLXXXIX - LA ÚLTIMA CENA DE N.S.J. CHRISTO}

Mira del Rey de los Reyes la última cena admirable, en que la sangre de Christo bebida es, manjar su carne. Assí, quando por la boca la Gracia de Dios entrare, ninguno ai más perezoso que el que sin ella se halle.

\section{CXC - LA ORACIÓN DEL HUERTO}

Alto sueño a los discípulos ocupa; Jesús despierto ora, tiembla i todo está en sudor de sangre embuelto. Afligido le conforta ángel embiado del Cielo. Aprende: al llevar la cruz Dios da a las fuerzas augmento.

$35 \mathrm{v}$.

\section{CXCI - PRISIÓN DEL HUERTO}

Antes le vendió, i aora ósculos piadosos finge Iscarioth, y a su Dios entrega por señas viles. No ai cosa más vergonzosa que la amistad que se finge: la que a tal maldad se atreve no avrá alguna a que no aspire. 


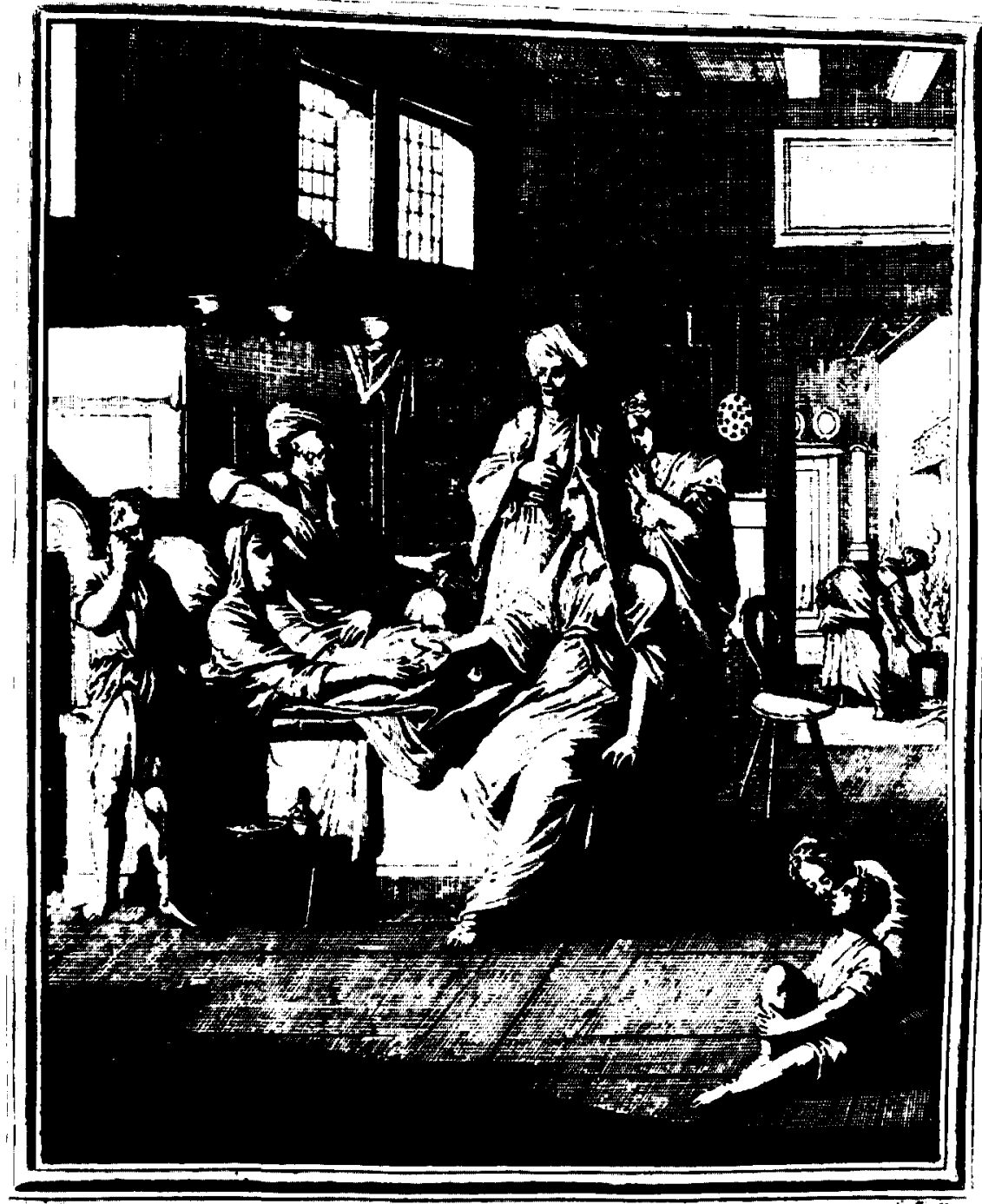

$\mathrm{M} \times \mathbf{T} \mathbf{T}, \mathbf{x} \times \mathbf{2}$

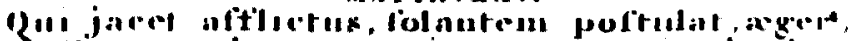

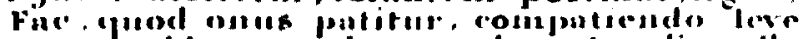

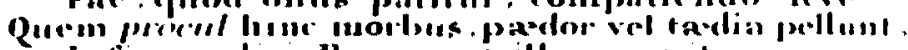

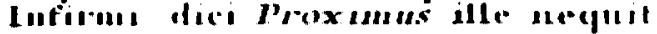

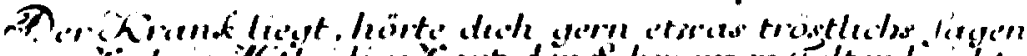

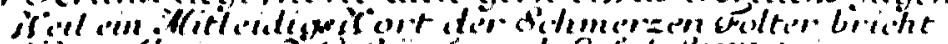

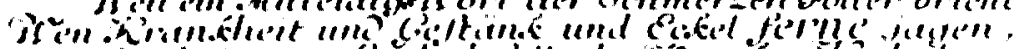

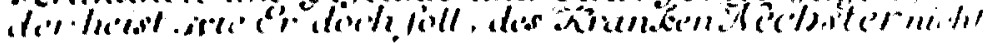




\section{CXCII - DELANTE DE CAIPHÁS}

¿Para qué son los testigos?

-dice Caiphás- Jesús veo;

de la muerte es puesto que hijo

se llama de Dios eterno.

Quando hace reo esta causa

del mundo al juicio perverso,

si es que quieres ser piadoso

no esperes sino tormentos.

\section{CXCIII - NEGACIÓN DE SAN PEDRO}

Al Maestro que con la espada

desnuda defendió Pedro, a aqueste mismo, perjuro niega aora el conocerlo.

A esta piedra esclava humilde pudo postrar en el suelo. ¿Quién juzgará que sus fuerzas bastán sólo a sostenerlo?

$36 r$.

\section{CXCIV - RESURRECCIÓN DE CHRISTO}

Christo con victoria sube, rompe lazos de la muerte, no ai ligaduras que manos o pies oprimir pudiessen. Te enseña a que vencedor de tus vicios puedas verte: vence tus inclinaciones, de tu alma lazos fuertes.

\section{CXCV - SANA CHRISTO AL ENFERMO QUE DESCUELGAN POR UN TECHO}

¡Ó, quánta fee! Desde un alto techo el enfermo descuelgan para que, ó piadoso Christo, con tu aiuda sanar pueda.

La enfermedad antes del alma, después la del cuerpo auientas con la palabra ${ }^{102}$ : assí que eres Verbo tus palabras prueban.

\section{CXCVI - SANA CHRISTO LA ENFERMA QUE TOCA SU ROPA}

Por todos lados le lados le oprime la turba, siente a la enferma que toca su ropa Christo, i da alivio a su miseria. ¿Quién, pues, a tu corazón, ó buen Jesús, no se llega? Que luego que nuestros males siente, al punto los remedia.

$36 \mathrm{v}$.

\section{CXCVII - LA VIEJA QUE HECHA SU LIMOSNA ${ }^{103}$}

La vieja que al oro i plata sus dos monedas añade, ésta como liberal más que los demás se aplaude, porque los demás sus dones por vana gloria reparten; ésta poco da,pero es sólo Dios a quien lo trae.

\section{CXCVIII - LA MAGDALENA UNGE LA CABEZA A CHRISTO EN CASA DEL FARISEO}

No, piadosa muger, este callado murmurio te obste que quiere que tus ünguentos se vendan i den a pobres. Unge la cabeza sacra que aora aún no tiene dónde se recline, i desta suerte nadie puede ser más pobre.

\section{CXCIX - CHRISTO SE APARECE A LA MAGDALENA EN TRAJE DE ORTELANO}

Suspende el passo i no quieras tocar, Magdalena, a Christo, que le estorba que a sus pies imprimas ósculos finos.

102. Marcos II.

103. Marcos XII. 
Hecho a rendirse al amor, huie aora de tus cariños por no volverse más tarde a sus celestes retiros.

$37 \mathrm{r}$.

\section{CC - LA ASENCIÓN [sic] DE N.S. A LOS CIELOS}

Veis aquí nos dexó Christo sus pisadas, ó mortales, quando desde el orbe nuestro a su patria ha de ausentarse. Feliz será aquel que nunca de sus pisadas se aparte, porque éste para los Cielos el camino mexor sabe.

\section{CCI - A ZACHARÍAS SE LE PRESENTA UN ÁNGEL ${ }^{104}$}

El incienso Zacharías quema, el ángel se presenta i que está Isabel preñada i de qué prole le enseña. Mientras que duda, enmudece: luego el que a ser su hijo venga no que voz es de algún hombre sino que es voz de Dios prueba.

\section{CCII - LA ENCARNACIÓN}

Gabriel, legado de Dios, desde los Cielos desciende; aora del linage humano la redempción ha de hacerse. Tan grande embaxada en solas dos palabras se contiene: da una la Virgen, después su palabra Dios concede.

$37 \mathrm{v}$.

\section{CCIII - VISITA A SANTA ISABEL}

Viene la Virgen que a Dios parirá; al enqüentro sale Isabel, se alegra i salta lo que en el útero trahe.
Ya el chicuelo se levanta aun quando su sol no nace. ¡Ó, qué bien de precursor sabrá el officio adaptarse!

\section{CCIV - NACIMIENTO DE CHRISTO}

La que pare es madre virgen, Dios es el que infante nace; entre secas pajas i entre mal pulidos brutos iace. La casa al desconocido cerrada, aora se aplaude; mas con todo ai quien a Dios quiera el corazón cerrarle.

\section{CCV - EL ÁNGEL ANUNCIA A LOS PASTORES EL NACIMIENTO DEL MESÍAS}

¿Por qué teméis, ó pastores, essa luz que resplandece a media noche, si della. falta vuestros ojos tienen? Id presto, que el Verbo carne se ha hecho, ved que no puede mirar tan grande pretigio alguno sin luz celeste.

$38 \mathrm{r}$.

\section{CCVI - PRESENTACIÓN AL TEMPLO, SIMEON Y ANNA}

La virgen madre lo ofrece, Simeón el niño recibe, proféticamente canta y la vieja Anna repite. Quiere que la muerte cierre sus ojos, que si felice vio a Jesús, nada gustoso queda en el mundo que miren.

\section{CCVII - J. CHRISTO EN EL TEMPLO CON LOS DOCTORES}

Buscando por todas partes por fin a Jesús enqüentran, ipero dónde! Entre doctores y allá en su casa paterna.

104. Lucas I. 
Afligido a veces buscas

a Jesús, que te consuela.

¿Por qué, pues, del templo i los

doctores sacros te alexas?

\section{CCVIII - CHRISTO RESUCITA A UN MUERTO}

Luego al punto que tu voz lo dice, éste se levanta; caídos estamos, ó Christo, quando levantarnos mandas.

Luego más es restituir la perdida vida al alma: no temas, pues, maior mal que el que esta muerte amenaza.

$38 \mathrm{v}$.

\section{CCIX - CARIDAD DEL SAMARITANO ${ }^{105}$}

Avía passado el levita, se avía ido el sacerdote i el samaritano sólo con su ayuda te socorre. Éste es el próximo: luego raro es este nombre al orbe, porque qualquiera desea huir del que infeliz conoce.

\section{CCX - MARTHA Y MARÍA}

A tu hermana, que se sienta i está atenta a la palabra de salud, a ésta Jesús a ti la antepone, ó Martha. La salud sola es la cosa que a qualquiera le hace falta; las demás, si a esto no importan, no debe el hombre estimarlas.

\section{CCXI - PARÁBOLA DE LA HIGUERA ${ }^{106}$}

La esperanza i el cuidado que puso el colono guarda a la higuera que el señor mandó del suelo arrancarla.

105. Lucas X.

106. Lucas XIII.

107 y 108. Lucas XV.
¿Hasta aquí no has dado fruto?

Teme segur afilada, quizás es último este año que para probarte falta.

$39 \mathrm{r}$.

\section{CCXII - LA OVEJA PERDIDA}

El hombre pastor es Dios, que a la oveja, a quien distrae su vago error, busca, enqüentra i alegre en sus hombros trae. También por sólo este hombre determinó el humanarse. ¿Quánto vale un alma que tanto pudo a Dios costarle!

\section{CCXIII - EL HIJO PRÓDIGO CON LOS CERDOS ${ }^{107}$}

A mí, miserable, aun las bellotas cerdosa hueste me quita, i ni aun de algarrobas mi hambre saciarse puede. Iré llorando a mi padre, que si pródigo en sus bienes pequé, pródigo en mi llanto quizá podré complacerle.

\section{CCXIV - EL HIJO PRÓDIGO VA A SU PADRE 108}

A su hijo que se vuelve recive su padre: invidia tiene el otro, porque teme su herencia disminuida. Aquél fue pródigo, a éste avaro el nombre se aplica; assí los caducos bienes en ser buenos nos limitan. 
$39 \mathrm{v}$.

\section{CCXV - EL RICO Y LÁZARO}

Aquí está el rico,i aquí

Lázaro, cuias heridas

lame el perro, está a sus puertas

i de hambre casi expira.

Pero ni a éste miserable

ni a aquél dichoso apellida;

ten memoria que la muerte

sola este título libra.

\section{CCXVI - EL RICO EN EL INFIERNO}

Aora el glotón del abismo

vecino es; pero del Cielo

Lázaro, antes infeliz,

dichoso después de muerto.

Entre las llamas vocea:

dame agua, Lázaro; pero

con razón niega una gota

a quien ni un bocado dieron.

\section{CCXVII - CHRISTO CURA A LOS DIEZ LEPROSOS}

Ó Jesús, tu Gracia libra

de la lepra a diez enfermos,

i uno sólo sano acude

a darte agradecimientos.

Uno, i es aquel a quien

tú perdonaste los ierros.

¡Ó maldad, si aun éste fuera

ingrato al bien que le han hecho!

$40 \mathrm{r}$.

\section{CCXVIII - MILAGRO DEL CIEGO}

¿Qué quieres que te haga? Assí

habla Jesús a este ciego,

i el ciego responde: sólo

el que yo vea te ruego.
Mira, esto Jesús mandó:

vee al punto. Tú a este Maestro

mira también, que si es sol

te dará claros reflexos.

\section{CCXIX - ZAQUEO ${ }^{109}$}

Apresúrate, Zacheo, presto el sycómoro dexa, Jesuchristo es quien te llama, ninguna tardanza tengas.

Éste tu huésped será; dexa no justas riquezas, que assí vacía tu casa de salud quedará llena.

\section{CCXX - JESUCHRISTO ENTRA EN GERUSALEM EN TRIUMFO}

Éste aclama, aquél vestidos y estotro olivas desprende; assí de Herusalem

aplaude a su rey la plebe.

Después con muchos oprobios desnudo en la cruz le extiende, que tales alteraciones la pompa del mundo tiene.

$40 \mathrm{v}$.

\section{CCXXI - LOS DISCÍPULOS DE EMAÚS}

A éstos instruies i llamas necios porque no comprehenden, o Christo, que de la cruz tu gloria alcanzada tienes. Siendo de la cruz el precio cienzia grande el conocerle, ique posean essa ciencia qué pocos el mundo tiene!

CCXXII - LAS BODAS DE CANAAM

A los esposos que junta el amor i Christo honra con su presencia, i aiuda con sus poderosas obras, 
quando falta lo mexor el agua en vino transfforma, i assí ya que Dios es bueno el gusto mismo lo informa.

\section{CCXXIII - JESUCHRISTO Y NICODEMO ${ }^{110}$}

Ó Nicodemo, al Messías que enseña, gustoso atiende, que de tu ánimo la noche como sol dissipar puede. Del agua y del Paracleto sagrado renacer debes; quien nuevo hombre en éstos se hace por hijo de Dios se tiene.

$41 \mathrm{r}$.

\section{CCXXIV - LA SAMARITANA}

Assí a la samaritana Jesús se acerca, i le ofrece él mismo las aguas vivas, de salud mystica fuente. También a éstas la combida, mas falta de amor celeste el calor, que agua ofrecida casi ninguno apetece.

\section{CCXXV - EL DE LA PISCINA}

Aquel que a médicas aguas nadie llevaba, presente tiene aora de su salud en Jesús la mexor fuente. Quando él sana, la esperanza, ó miserables, os vuelve de que a quien no tiene hombre $e^{111}$ Dios mismo a assistirle viene.

\section{CCXXVI - PANES Y PESES}

Tubieron hambre; el prodigio tuio fue que apacentasses con poca comida, ó Christo piadoso, a tantos millares.
El que aora para pocos tantas comidas se gasten cierto es que lo que hace el maligno espíritu con sus artes.

$41 \mathrm{v}$.

\section{CCXXVII - LOS JUDÍOS QUIEREN LAPIDAR A JESÚ'S 112}

Ó perversa gente, piedras buscas i tirarlas quieres contra aquel que ser Dios tales i tantas señas convienen. ¡Ó qué bien! No quedará piedra que entera se muestre en esta ciudad que da piedras que a los justos hieren.

\section{CCXXVIII - JESÚS CURA AL CIEGO DE NACIMIENTO}

Ó Christo, a aquel que sus padres míseros ciego engendraron tú haces que al punto consiga la vista, lodo aplicando ${ }^{113}$. El phariseo del templo le echa porque havía mirado; luego entre los ciegos sólo no hace la invidia su estrago.

\section{CCXXIX - EL BUEN PASTOR}

Uno se para, otro huie, éste libra sus ovejas aun con riesgo de su vida, el otro al lobo las dexa. Si aquél o éste es buen pastor, sin preguntarlo se muestra; pero es necessario hallar pastores que buenos sean.

110. Juan III.

111. Juan V.

112. Juan VIII.

113. Juan IX. 


\section{CCXXX - RESURECIÓN [sic] DE LÁZARO}

De no acostumbrada voz

Lázaro llamado sale

después que por quatro días

su urna le guarda cadáver.

Aprended, sacros doctores, que en la voz no ha de cessarse $e^{114}$

porque desta necessitan

las almas que en vicios iazen.

\section{CCXXXI - CHRISTO LAVA LOS PIES A SUS APÓSTOLES}

Ante estos pies se arrodilla a quien humillarse deben el cielo, tierra e infierno con sumisión reverente. Si te postra alguna vez a los pies de otro tu suerte mira.a Jesús, i en su exemplo tu corazón se renueve.

\section{CCXXXII - CHRISTO ANTE CAIFÁS}

Este rostro de Jesús que visto felices hace, jay de mí!, diextra inhumana, más que bárbara, herir sabe. Si una palabra no puedes sufrir, el rostro que tales afrentas sufrió, ó sobervio, ¿cómo puede no templarte?

42 v.

\section{CCXXXIII - ECCE HOMO}

Mira al hombre que ser Dios tanta paciencia convence, i mira hombres que la ira el ser hombres les desmiente. Si otra vez crucificarle es lo que tus culpas quieren, te igualas con los judíos, peor que las fieras eres.

\section{CCXXXIV - CHRISTO EN LA CRUZ}

En medio Jesús, de aquí i allí un ladrón i otro pende; éste en la cruz se hace bueno i aquél maldito perece. ¡Ó mortales! Aprended a esperar i a temer, que éste de salvación da esperanza como aquél miedos ofrece.

\section{CCXXXV - DESCENDIMIENTO DE LA CRUZ}

Tú que de la cruz a Christo ves baxar en esta imagen, ¿le ofreces tu corazón porque como urna le guardes?

Renuévale el monumento en que gustoso descanse; Jesús para entrar en él limpio i nuevo quiere hallarle.

$43 \mathrm{r}$.

\section{CCXXXVI - CHRISTO Y SANTO TOMÁS}

Creió luego que las vio al mirar Thomás las llagas; ó mi Dios i mi Señor, lleno de su amor exclama. Crees, mas con mente fixa estas llagas no reparas, porque en el amor de Dios tu corazón frío estaba.

\section{CCXXXVII - CHRISTO CON SAN PEDRO}

¿Qué cuidado de Juan tienes si assí quiero que se quede ${ }^{115}$ Pero a ti, ó Pedro, la fuerza te hará ir donde no quieres. Sígueme, esto a Pedro dixo; $i$ a todos nos comprehende, que su cruz a cada uno, no la del otro, conviene.

\section{Juan XI.}

115. Juan XXI. 


\section{$44 \mathrm{r}$.}

\section{CCXXXVIII - LA VENIDA DEL ESPIRITU SANTO}

Sancto Spíritu se oculta en el fuego que parece lengua, i sobre las cabezas de los discípulos viene.

Si de sus sagrados pechos el celeste amor es huésped, por su buena o mala lengua qualquiera conocer puede.

$43 \mathrm{v}$.

\section{CCXXXIX - SAN PEDRO CURA A UN COXO}

Quando la mano te da e? coxo i limosna pide, que se levante en el nombre de Jesús, Pedro, le dices. Se levanta, anda i siguiendo a un coxo con passos firmes cinco mill hombres el recto camino de la fee siguen.

\section{CCXL - MUERE A LOS PIES DE SAN PEDRO EL AVARIENTO ${ }^{116}$}

El engañoso que oculta el precio en que vendió el campo, éste ante los pies de Pedro padece el último estrago. Si este castigo el oculto dinero, ¿quál el robado merece de Dios? Si quieres vivir, no seas avaro.

\section{CCXLI - MARTIRIO DE SAN ESTEVAN}

Con estas piedras cruel gente a Esteban la diadema eterna labra, i no obstante él mismo por ellos ruega. Por las piedras el primero sube al Cielo, i les enseña a los que siguen que es dura la senda que al Cielo lleva.

\section{CCXLII - EL APÓSTOL SAN FELIPE BAPTISA A EL ENUCO [sic]}

Enseñándole Philipo

el eunucho lo que lee ęntiende, i la fee de Christo con todo el corazón quiere. Presente el río, del carro uno i otro ya desciende; allí el etíope laba ${ }^{117}$, i nada impossible emprende.

\section{CCXLIII - CONVERSIÓN DE SAN PABLO}

El ciego a quien tú derribas al punto, ó Christo, comprehende para conocer tu luz la fuerza que el rayo tiene. Luego la deidad con esta luz los errados convierte, con la qual los que antes eran ciegos, con vista se advierten.

\section{CCXLIV - SAN PEDRO RESUCITA A THABITA ${ }^{118}$}

Mira cómo resusita viva a los ruegos de Pedro Thabita, que muerta era causa a tanto sentimiento. Digna es de vivir dos veces, aunque qüente años immensos, la que en su vida y avisos tantos vivir aprendieron.

$44 \mathrm{v}$.

\section{CCXLV - EL ÁNGEL SE APARECE AL CENTURIÓN ${ }^{119}$}

Mira cómo el ángel viene i al centurión le señala la verdadera salud, por quién i cómo ha de hallarla. No admires de la Deidad esta desusada gracia, que este prodigio merece la piedad que en él se halla.

116. Hechos V.

117. Hechos VIII.

118- Hechos IX.

119. Hechos X. 
CCXLVI - SAN PEDRO AD VÍNCULA ${ }^{120}$

Pedro libre de prisiones se levanta, i de la cárcel, la puerta de hierro abierta, guiándole el ángel sale.

La Iglesia humilde por Pedro

lo alcanza assí. Aprende: grande es la efficazia que tienen

ruegos que de una fee nacen.

\section{CCXLVII - CASTIGO DE ELYMAS ${ }^{121}$}

Apenas se opone Elymas, famoso en mágicas artes, a Paulo, quando infeliz de ambos ojos ciego yace. Milagros Paulo duplica porque Sergio a Christo sabe conocer; conque a este ciego pudo assí la vista darle.

$45 \mathrm{r}$.

\section{CCXLVIII - SAN PABLO SANA A UN COXO}

A este coxo que tenía ya la fee en su pecho impressa levantarse, ó Paulo, mandas; se levanta, corre, vuela. Si pasamos, si seguimos floxos de virtud la senda, o esta muerta nuestra fee o por lo menos enferma.

\section{CCXLIX - SAN PAULO EN EL ARÉOPAGO}

Quando la resurrección Paulo en Athenas enseña, éste cree, aquél se para, ríe éste, el otro se ausenta.
¿Los novísimos no quiere oír quien lo nuevo desea? I es que resucitar teme el que antes el morir tiembla.

\section{CCL - SAN PAULO ANTE EL REY AGRIPPA $^{122}$}

A quien admiran hablando el rey Agrippa i la reina sin razón, ó Festo, juzgas que es locura la que ostenta. En obsequio de la fee Paulo assí captivar dexa su mente, i si tú supiesses imitaras tal demencia.

$45 \mathrm{v}$.

\section{CCLI - SAN PAULO EN MALTA ${ }^{123}$}

Quando la vívora cae arrojada, sin que ofenda la mano que muerde, el pueblo a Paulo por Dios venera. Malteses, no esto creais sino lo que Paulo enseña: porque Dios mismo a vosotros por su boca os amonesta.

\section{CCLII - EL ÁNGEL DEL APOCALIPSE Y SIETE CANDELEROS ${ }^{124}$}

Estos siete candeleros denotan los pueblos fieles, i también las siete estrellas siete prelados refieren. La voz del Divino Verbo es la espada; ó reo, teme su herida, porque no ai otra que hiera más gravemente.

\footnotetext{
120. Hechos XII.

121. Hechos XIII.

122. Hechos XXV, XXVI.

123. Hechos XXVIII.

124. Apocalipsis I.
} 


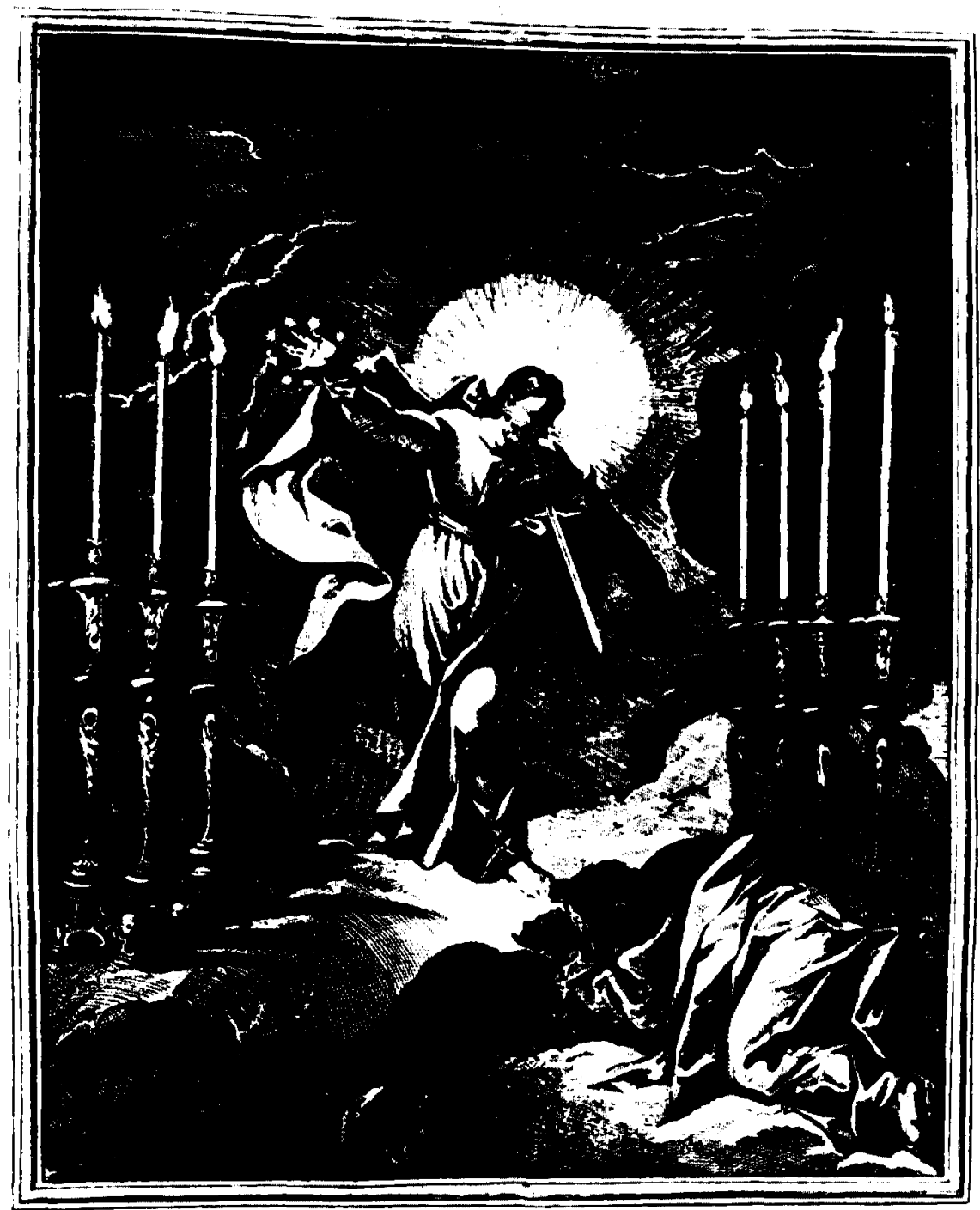

Arocat. . .

Candelabra notant populos sopterna idlelles Sunt qurodque septeni Presulis astra typu:

Divimi Verbi est vox erisis. ab illus 1ctu

Qui reus es gravion ham nequit esse cave.

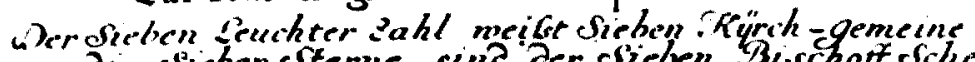

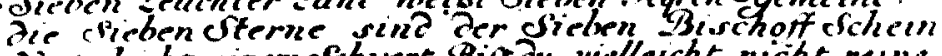

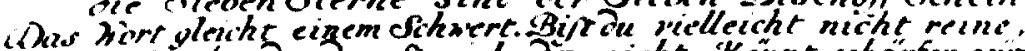

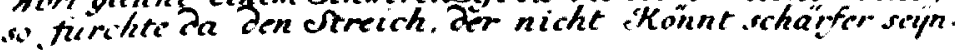

El ángel del Apocalipsis 


\section{CCLIII - LOS ANCIANOS Y LOS QUATRO ANIMALES ${ }^{125}$}

Los ancianos a los santos, los quatro animales luego notan los evangelistas, i la voz de Dios los truenos. Si a la evangélica luz su vista alguno no ha abierto, de la vista de Dios debe separarse como ciego.

$46 \mathrm{r}$.

\section{CCLIV $^{126}$ - LAS PLAGAS SOBRE LA TIERRA}

En la misma hoguera en que ruegos de justos se ofrecen como incienso, sus trisulcos ${ }^{127}$ rayos Némesis enciende. A estas llamas la tercera parte del mundo perece; aprende, ó impío, i a Dios, que es el mismo fuego, teme.

\section{CCLV - EL SOL SOBRE DOS COLUMNAS EN MAR Y TIERRA}

Este rostro del Sol gozos de luz eterna promete, i este iris sereno paz a los piadosos ofrece. Oprimido en tierra i mar el mundo que se envanece, el pie de bronce $i$ de fuego de justa Némesis siente.

\section{EL DRAGÓN ES PRECIPITADO 128}

$46 \mathrm{v}$.

\section{CCLVI - EL PRÍNCIPE DEL INFIERNO EN EL ABISMO}

Ante el tribunal del juez todo muerto se presenta; vivo será el que en el libro de la vida se numera. El príncipe del Averno autor de vicios se encierra, i la libertad del mundo gime en el abismo presa.

\section{CCLVII - LA JERUSALEM CELESTE}

Ves la admirable ciudad de Jerusalem Celeste, que toda de piedras finas más que el cristal resplandece. El que es piadoso no aquí llore el mundo que perece, que casas sólo de lodo la caduca tierra tiene.

total 260 láminas ${ }^{129}$

125. Apocalipsis IV.

126. Falta en el ms. un epigrama por traducir.

127. Triples.

128. Falta la estrofa correspondiente a este título.

129. En realidad, el ms. incluye 257 estrofas. 


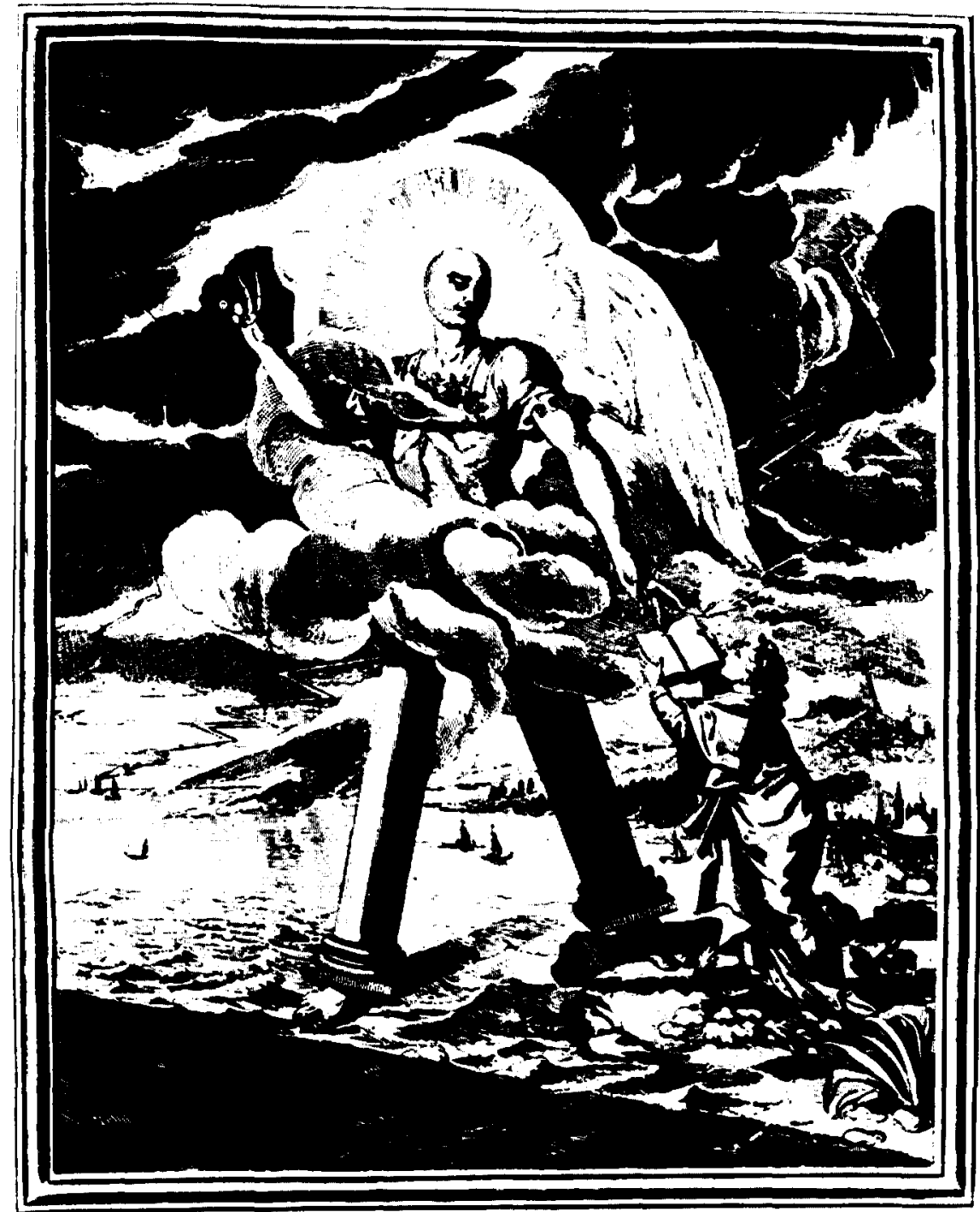

Hoc Solis facies Aroc: $x$.

It pacem hac Iris spondet anoua, pirs Arco et ignito. terris contrirus et uudis

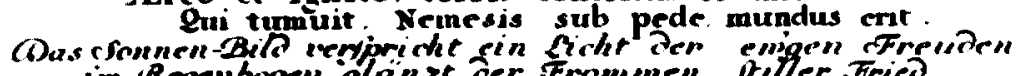

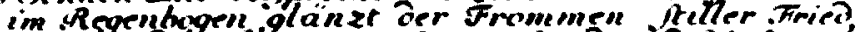

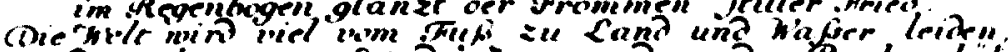

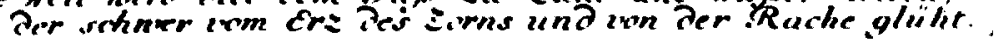

El Sol sobre dos columnas 
$47 \mathrm{r}$.

\section{ÍNDICE DE LAS OBRAS DE LUZÁN}

Tradución [sic] del Pange Lingua ${ }^{130}$

Soneto - El hijo de Laertes ${ }^{131}$

idm. - a su Bethulia 132

idm. - sale de tierra ${ }^{133}$

idm. - poeta cordovés de los Demonios ${ }^{134}$

idm. - Dn. Juan Clemente no ${ }^{135}$

Traducción de los Epinicios Latinos al Delphín por la victoria de Fontenoi ${ }^{136}$

Octavas en la abertura de la Academia de las tres Bellas Artes en 1752 - está impresa en la distribución de Premios ${ }^{137}$

El Juicio de Paris - en la entrada de Fernando VI en Madrid, año $1746^{138}$

Romance a la Duquesa de Bervic embiándole el Poema de el Juicio de Paris ${ }^{139}$

Canción a Dn. Manuel de Roda sobre el Cometa del año $1743^{140}$

La Primavera, poema ${ }^{141}$

Hero y Leandro, ydilio anacreóntico ${ }^{142}$

$47 \mathrm{v}$.

\section{Canciones}

Reprimir tienta en vano ${ }^{143}$

idm: - ahora es tiempo Euterpe ${ }^{\uparrow 44}$

130. BAE LXI, p. 119. Ms. 3743 de la Biblioteca Nacional de Madrid (Obras Manuscritas de D. Ignacio Luzán Claramunt de Suelves y Gurrea), fol. 1 r. y v.

131. Ms. $3743,2 \mathrm{r}$.

132. Ibid. 2 r. y v. BAE cit. p. 119 con variantes.

133. Ibíd. $2 \mathrm{v}$.

134. Ibíd 2 v. $-3 \mathrm{r}$.

135. Ibíd $3 \mathrm{r}$.

136. Citado en ms. 17521. En ms. 3743, 3 v. - 4 r.

137. Citado en ms. 17521. En ms. 3743, 4 r. $-7 \mathrm{v}$.

138. BAE cit. p. 111 . Ms. 3743,8 r. -22 v.

139. Cit. ms. 17521. Ms. 3743,23 r. -27 v.

140. Cit. ms. 17521. Ms. 3743,28 r. $-30 \mathrm{v}$.

141. Cit. ms. 17521 . Ms. 3743,31 r. -34 r.

142. BAE cit. p. 120 . Ms. 3743,42 r. -49 r.

143. Ms. 3743,49 v. -52 v.

144. BAE cit. p. 115. Canción primera sobre Orán. Ms. 3743,52 v. - 56 r. 
idm. - dame segunda vez ${ }^{145}$

Medea a Jasón, epístola de Ovidio, tradución [sic] ${ }^{146}$

Tradución [sic] de la sátyra de Horacio ibam forte via sacra ${ }^{147}$

Versión del psalmo Miserere ${ }^{148}$

Tradución [sic] de las Epigramas de la historia del viejo y nuevo Testamento, en estampas hechas por Christóval Worgelio [sic] en Nüremberg. Copiadas las Epigramas de el original y propia letra de Luzán que posee Dn. Manuel de Yera en Cádiz.

145. BAE cit. p. 116. Canción segunda sobre Orán. Ms. 3743, 56 v. - 59 v.

146. Cit. ms. 17521. Ms. 3743,59 v. -66 r.

147. Cit. ms. 17521. Ms. 3743,66 v. -70 r.

148. Cit. ms. 17521 . Ms. 3743,70 v. -72 r. 